\title{
Two cation exchange models for direct and inverse modelling of solution major cation composition in
}

equilibrium with illite surfaces.

ACCEPTED VERSION NOV 2006

Christophe Tournassat ${ }^{*}$, Hélène Gailhanou, Catherine Crouzet, Gilles Braibant, Anne Gautier, Arnault Lassin, Philippe Blanc, Eric C. Gaucher

BRGM, French Geological Survey, Environment and Process Department, 3 Av. Claude Guillemin, BP 6009, 45060 Orléans Cedex 2, France

* Corresponding author: c.tournassat@,brgm.fr

BRGM, EPI/DES

3 Av. Claude Guillemin

BP 6009, 45060 Orléans Cedex 2, France

Tel: +33238644744

Fax: +33238643062 


\begin{abstract}
$\mathrm{Na}-\mathrm{K}, \mathrm{Na}-\mathrm{Ca}$ and $\mathrm{Na}-\mathrm{Mg}$ exchange isotherms were performed on the fine fraction $(<2 \mu \mathrm{m})$ of Imt-2 illite samples at a total normality of about $0.005 \mathrm{~mol} / \mathrm{L}$ in anionic chloride medium. The derived selectivity coefficients for $\mathrm{Na}-\mathrm{K}, \mathrm{Na}-\mathrm{Ca}$ and $\mathrm{Na}-\mathrm{Mg}$ were found to vary as a function of the exchanger composition and compared well with the data collected in the literature for similar experimental conditions. Two models were built to reproduce the data: the first was a multi(2)-site model with constant Gaines and Thomas selectivity coefficients; the second was a one-site model taking into account surface species activity coefficients.

The results of the models were in rather good agreement with both our data and literature data. The multi-site model proved to be efficient in predicting the exchanger composition as a function of the Na-Ca-Mg-K concentrations in solution, whereas the one-site model proved to be a better approach to derive the $\mathrm{Na}-\mathrm{Ca}-\mathrm{Mg}-\mathrm{K}$ concentrations in solution based on the knowledge of the exchanger composition and the total normality of the solution. The interest of this approach is illustrated by the need for major cation solute concentration predictions in compacted clay for the characterization of nuclear deep disposal host rock repositories.
\end{abstract}




\section{Introduction}

The objective of the present study was to provide an up-to-date cation exchange constant database for $\mathrm{Na}, \mathrm{K}, \mathrm{Ca}$ and $\mathrm{Mg}$ on illite surfaces. Cation exchange databases are easily found in chemical reaction databases provided with speciation calculation codes, such as PHREEQC2 (PARKHURST and APPELO, 1999). However, (i) these databases contain no or few references to published results and (ii) the tabulated selectivity coefficients should be considered for montmorillonite only.

Knowledge of reliable cation exchange selectivity coefficients for major cations on illite is of importance in the context of nuclear waste deep disposal studies in order to simulate the porewater solute composition. The exchanger composition provides information about the relative amount of $\mathrm{Na}^{+}, \mathrm{K}^{+}, \mathrm{Ca}^{2+}, \mathrm{Mg}^{2+}$ in solution:
$\mathrm{NaX}+\mathrm{K}^{+} \Leftrightarrow \mathrm{KX}+\mathrm{Na}^{+}$
$K_{N a / K}$
Reaction 1
$2 \mathrm{NaX}+\mathrm{Ca}^{2+} \Leftrightarrow \mathrm{CaX}_{2}+2 \mathrm{Na}^{+} \quad K_{\mathrm{Na} / \mathrm{Ca}}$
Reaction 2
$2 \mathrm{NaX}+\mathrm{Mg}^{2+} \Leftrightarrow \mathrm{MgX}_{2}+2 \mathrm{Na}^{+} \quad K_{\mathrm{Na} / \mathrm{Mg}} \quad$ Reaction 3

where $\mathrm{X}^{-}$represents one mole of the exchanger. The exchanger composition, an easily measurable parameter in compacted clayey rocks, is then an "image" of the porewater major cation composition, which cannot be directly characterized by water extraction and concentration measurements due to the low water content of these rocks (BRADBURY and BAeyens, 1998; PeArson et al., 2003; GAUCher et al., Accepted). The following calculation shows how to obtain the $\mathrm{Na}^{+}$concentration assuming that (i) the exchanger composition is 
known, (ii) the sum of the equivalent concentrations of $\mathrm{Na}^{+}, \mathrm{K}^{+}, \mathrm{Ca}^{2+}, \mathrm{Mg}^{2+}$ is equal to the sum of the equivalent concentrations of $\mathrm{Cl}^{-}$and $\mathrm{SO}_{4}{ }^{2-}$ (i.e. neglecting $\mathrm{H}^{+}$and other minor cation contributions) and (iii) the exchange selectivity coefficients are known.

In the following, the Gaines and Thomas convention is used to express the equilibrium equation with the exchanger phase (e.g. SPOSITO, 1981). According to this convention, the activity of an exchanged species is equal to the equivalent fraction occupied by the cation on the exchanger phase, times an activity coefficient. This activity coefficient is here set equal to 1 for the analysis that follows (Eqs. 1 to 8 ).

Exchange reaction equilibria then lead to the following equations:

$$
\begin{aligned}
& K_{e x}^{\mathrm{Na} / \mathrm{Mg}}=\frac{\left\{\mathrm{Na}^{+}\right\}^{2}}{\left\{\mathrm{Mg}^{2+}\right\}} \times \frac{E_{\mathrm{MgX}_{2}}}{E_{\mathrm{NaX}}^{2}} \\
& K_{e x}^{\mathrm{Na} / \mathrm{Ca}} \frac{\left\{\mathrm{Na}^{+}\right\}^{2}}{\left\{\mathrm{Ca}^{2+}\right\}} \times \frac{E_{\mathrm{CaX}_{2}}}{E_{\mathrm{NaX}}^{2}} \\
& K_{e x}^{\mathrm{Na} / \mathrm{K}}=\frac{\left\{\mathrm{Na}^{+}\right\}}{\left\{\mathrm{K}^{+}\right\}} \times \frac{E_{\mathrm{KX}}}{E_{\mathrm{NaX}}}
\end{aligned}
$$

where values in brackets are representative of species activities and $E_{i}$ is representative of the equivalent fraction on the exchanger of surface species $i$. The concentrations of each solution species as a function of the $\mathrm{Na}^{+}$concentration are then:

$$
\begin{aligned}
& {\left[\mathrm{Mg}^{2+}\right]=\frac{\gamma_{\mathrm{Na}^{+}}{ }^{2}}{\gamma_{\mathrm{Mg}^{2+}}} \times \frac{\left[\mathrm{Na}^{+}\right]^{2}}{K_{e x}^{\mathrm{Na} / \mathrm{Mg}}} \times \frac{E_{\mathrm{MgX} X_{2}}}{E_{\mathrm{NaX}}{ }^{2}}} \\
& {\left[\mathrm{Ca}^{2+}\right]=\frac{\gamma_{\mathrm{Na}^{+}}{ }^{2}}{\gamma_{\mathrm{Ca} a^{2+}}} \times \frac{\left[\mathrm{Na}^{+}\right]^{2}}{K_{e x}^{\mathrm{Na} / \mathrm{Ca}}} \times \frac{E_{\mathrm{CaX}_{2}}}{E_{\mathrm{NaX}}{ }^{2}}} \\
& {\left[\mathrm{~K}^{+}\right]=\frac{\gamma_{\mathrm{Na}^{+}}}{\gamma_{\mathrm{K}^{+}}} \frac{\left[\mathrm{Na}^{+}\right]}{K_{\mathrm{ex}}^{\mathrm{Na} / K}} \times \frac{E_{\mathrm{KX}}}{E_{\mathrm{NaX}}}}
\end{aligned}
$$

where $\gamma_{i}$ is the activity coefficient of the species $i$ in solution. These coefficients can be obtained using Debye-Hückel, Davies or Pitzer equations. 
By combining Eqs. 4 to 6 with the electro-neutrality relationship:

$$
\left[\mathrm{Cl}^{-}\right]+2 \times\left[\mathrm{SO}_{4}^{2-}\right]=2 \times\left[\mathrm{Ca}^{2+}\right]+2 \times\left[\mathrm{Mg}^{2+}\right]+\left[\mathrm{Na}^{+}\right]+\left[\mathrm{K}^{+}\right] \quad \text { Eq. } 7
$$

where values in square brackets are concentrations, one obtains:

$$
\begin{aligned}
& \frac{2 \times \gamma_{\mathrm{Na}^{+}}{ }^{2}}{E_{\mathrm{NaX}}{ }^{2}} \times\left[\mathrm{Na}^{+}\right]^{2} \times\left(\frac{E_{\mathrm{MgX} X_{2}}}{\gamma_{\mathrm{Mg}^{2+}} \times K_{e x}^{\mathrm{Na} / \mathrm{Mg}}}+\frac{E_{\mathrm{CaX} 2}}{\gamma_{\mathrm{Ca}^{2+}} \times K_{e x}^{\mathrm{Na} / \mathrm{Ca}}}\right) \\
& +\left[\mathrm{Na}^{+}\right] \times\left(1+\frac{\gamma_{\mathrm{Na}^{+}}}{\gamma_{\mathrm{K}^{+}}} \frac{\left[\mathrm{Na}^{+}\right]}{\left.\mathrm{K}_{\mathrm{ex}}^{\mathrm{Na} / \mathrm{K}} \times \frac{E_{\mathrm{KX}}}{E_{\mathrm{NaX}}}\right)}\right. \\
& -\left[\mathrm{Cl}^{-}\right]-2 \times\left[\mathrm{SO}_{4}^{2-}\right] \\
& =0
\end{aligned}
$$

Bicarbonate concentrations are neglected in the electro-neutrality relationship, because they were found to represent a minor fraction $(\sim 2 \%)$ of the anionic charge in the considered clayey systems (e.g. GAUCHER et al., Accepted, for a Callovian-Oxfordian formation with total normality about $0.05-0.1 \mathrm{~mol} / \mathrm{L}$, or PEARSON et al., 2003 for an Opalinus Clay formation). Second order equations similar to Eq. 8 can be derived for $\mathrm{K}, \mathrm{Ca}$ and $\mathrm{Mg}$. One obtains five second order equations with ten unknown parameters (the five concentrations and the associated activity coefficients). Debye-Hückel, Davies or Pitzer (for concentrated solutions) equations give five other independent equations for the activity coefficients. Hence, the mathematical system is fully constrained (ten unknowns with ten independent equations) and the $\mathrm{Na}, \mathrm{K}, \mathrm{Ca}$ and $\mathrm{Mg}$ concentrations can be calculated, based on the exchanger composition and the $\mathrm{Cl}^{-}$and $\mathrm{SO}_{4}{ }^{2-}$ concentrations (and possibly other anions that contribute significantly to the total anion equivalent concentration). However, a good precision on the selectivity coefficient value is needed to obtain reliable concentration values. The present work aims at obtaining these selectivity coefficients for $\mathrm{Na}, \mathrm{K}, \mathrm{Ca}$ and $\mathrm{Mg}$ on illite.

Data collected from the literature is widely used in the following work together with new exchange data obtained in our laboratories. Data from the literature always originated from exchange experiments where both the solution and the exchanger composition were 
measured. New exchange data were obtained in the framework of the French Nuclear Waste Management Agency (ANDRA) investigation program on the clayey formation surrounding the French Underground Laboratory (URL) in Bure (Meuse Haute-Marne, France).

\section{Materials and experimental methods}

Chemicals. All solutions and suspensions were prepared with Millipore Milli-Q 18 $\mathrm{M} \Omega$ water. $\mathrm{NaCl}, \mathrm{KCl}, \mathrm{MgCl}_{2}$ and $\mathrm{CaCl}_{2}$ solutions were prepared from analytical grade salts.

Clay material preparation. IMt-2 clay sample material was obtained from the Source Clays Repository (http://www.clays.org/sourceclays/SourceClaysCCM.html). After saturating the suspension with $\mathrm{NaCl}(0.5 \mathrm{~mol} / \mathrm{L})$, it was successively treated with a $\mathrm{H}_{2} \mathrm{O}_{2} / \mathrm{HNO}_{3}$ mixture $(\mathrm{pH} \sim 2)$ to remove carbonate and organic matter impurities, then with a mixture of sodium hydrosulphite/ $\mathrm{HCl}\left(\mathrm{pH}^{3}\right)$ to remove iron and manganese oxi(hydroxi)des. Each of the preceding treatments was followed by careful washing with deionised water. The clay was then washed with a mixture of $\mathrm{NaCl}(1 \mathrm{~mol} / \mathrm{L})$ and $\mathrm{HCl}\left(10^{-4} \mathrm{~mol} / \mathrm{L}\right)$. The fine fraction $(<2$ $\mu \mathrm{m})$ of the sample was then isolated by sedimentation, redispersed in $\mathrm{NaCl}(1 \mathrm{~mol} / \mathrm{L})$ and washed with deionised water until the supernatant exhibited a negative response to the silver nitrate test.

Cation exchange isotherms. $\mathrm{Na}-\mathrm{K}, \mathrm{Na}-\mathrm{Ca}$ and $\mathrm{Na}-\mathrm{Mg}$ exchange isotherms were performed at a total normality of $\sim 0.005 \mathrm{~mol} / \mathrm{L}$ in chloride anionic background. The chloride anionic background was preferred to a perchlorate background since it better represents the natural systems studied in our laboratories. Moreover, the effect of cation-anion pairing is expected to be limited at this concentration in the light of results obtained with 
montmorillonite (SpOSITO et al., 1983a; SPOSITO et al., 1983b; FletChER and SPOSITO, 1989; Tournassat et al., 2004b; Charlet and Tournassat, 2005; Ferrage et al., 2005). The method described in TOURNASSAT et al., 2004b was used to perform exchange isotherms, with the exception of the use of cobalt hexamine instead of ammonium acetate as an extracting agent of exchanged cations (CIESIELSKI and STERCKEMAN, 1997). The $\mathrm{pH}$ of the experiment was 5.

\section{Presentation, thermodynamic convention and interpretation of the results.}

The cation exchange selectivity coefficient is representative of the relative affinity of the exchanger for two considered cations. In the case of a $\mathrm{Na} / \mathrm{K}$ or $\mathrm{Ca} / \mathrm{K}$ exchange, selectivity coefficient values above 1 would denote an affinity for $\mathrm{K}$ greater than for $\mathrm{Na}$ and $\mathrm{Ca}$, meaning a "preference" of the surface for $\mathrm{K}$. The selectivity coefficient is not a thermodynamic exchange constant, since it varies as a function of the exchanger composition (e.g. JENSEN, 1973).

In the following, two main thermodynamic conventions for cation exchange selectivity coefficients will mainly be used: the Gaines and Thomas convention described above and the Vanselow convention (e.g. SPOSITO, 1981; MCBRIDE, 1994). The Vanselow selectivity coefficient of a monovalent-monovalent exchange (e.g. Na-K) is:

$$
K_{v}^{N a / K}=\frac{N_{K} \times\left\{\mathrm{Na}^{+}\right\}}{N_{N a} \times\left\{K^{+}\right\}} \quad \text { Eq. } 9
$$

and the Vanselow selectivity coefficient of a divalent-monovalent exchange (e.g. Ca-K) is:

$$
K_{v}^{C a / K}=\frac{\left\{\mathrm{Ca}^{2+}\right\} \times N_{K}^{2}}{N_{C a} \times\left\{K^{+}\right\}^{2}}
$$

where $N_{i}$ represents the molar fraction of the cation $i$ on the exchanger and where values in brackets represent the activity of solute species. Knowing the cation exchanger composition 
makes it possible to switch easily from one convention to the other: in the case of homovalent exchange, Gaines and Thomas and Vanselow selectivity coefficient values are identical and for monovalent / divalent exchange, the following formula applies:

$$
K_{G T}^{\mathrm{Na} / \mathrm{Ca}}=K_{v}^{\mathrm{Na} / \mathrm{Ca}} \times \frac{N_{\mathrm{Na}}{ }^{2} \times E_{\mathrm{Ca}}}{E_{\mathrm{Na}}{ }^{2} \times N_{\mathrm{Ca}}}
$$

On the one hand, the Gaines and Thomas convention is very useful in the calculation approach shown by Eqs. 1 to 8 . Moreover, this calculation convention is available in all numerical speciation codes (e.g. CRUNCH, STEEFEL, 2001, GEOCHEMIST WORKBENCH, Bethke, 1996, PHREEQC2, PARKhurst and Appelo, 1999), as opposed to the Vanselow convention (especially in PHREEQC2). On the other hand, the Vanselow convention is the only one that enables the calculation of exchange species activity coefficients directly as a function of their variation with changes in the exchanger composition (SPOSITO, 1989), an approach that is developed at the end of this paper. The data in the figures are always presented at least in the Vanselow convention in order to enable comparison between the figures. The exchanger composition is expressed in the following in terms of the equivalent exchanged fraction of the cations participating in the exchange process, i.e. $E_{N a}, E_{K}, E_{C a}$ and $E_{M g}$ (SPOSITO, 1981). The activity of solute species was computed using PHREEQC v2.12 and the Llnl.dat database provided with the software (PARKHURST and APPELO, 1999, http://wwwbrr.cr.usgs.gov/projects/GWC_coupled/phreeqc/).

\section{Experimental results}

The complete set of data obtained in this study and from the literature is given in the table of Electronic Appendix 1. It can be seen from this table that the $K_{v}$ values calculated for divalent/monovalent cation exchange on the basis of the data reported by Thellier and Sposito 
(Thellier and Sposito, 1988; Thellier and Sposito, 1989b) are different from the values reported by these authors by a factor 2 , probably due to a misuse of equivalent $/ \mathrm{kg}$ instead of mole/kg for divalent cations in Thellier's $K_{v}$ calculation.

Results for $\mathrm{Na} / \mathrm{K}$ exchange selectivity coefficients are shown in Fig. $1 . K_{v}{ }^{\mathrm{Na} / \mathrm{K}}$ is shown to vary as a function of the exchanger occupancy. This has already been shown for $\mathrm{Na} / \mathrm{K}$ exchange on montmorillonite with the same trend of $K_{v}^{N a / K}$ decreasing as a function of increasing $\mathrm{E}_{\mathrm{K}}$ (JENSEN, 1973). One can also note a large scattering of results in the low K occupancy zone $\left(E_{K}<0.2\right)$, the data points obtained in this study for the $\mathrm{Na} / \mathrm{Ca}$ and $\mathrm{Na} / \mathrm{Mg}$ experiments having the highest values and showing no clear trend. This behaviour could be due to several experimental reasons. The first is the possible effect of $\mathrm{pH}$ (the $\mathrm{pH}$ of the present experiment was 5 whereas the $\mathrm{pH}$ of the Thellier and Sposito experiment was 7), although Thellier et al. observed little effect of $\mathrm{pH}$ on the Na-Ca selectivity coefficient (THELLIER et al., 1992). The nature of the extracting reagent could also have an effect on the $\mathrm{K}$ desorption (cobalt hexamine vs. ammonium). Finally, we used the $<2 \mu \mathrm{m}$ fraction whereas Thellier and Sposito used $\mathrm{a}<115 \mu \mathrm{m}$ fraction. This latter effect is certainly predominant with an increase in the effect of edge sorption sites as the particle size decreases.

Results for $\mathrm{Na} / \mathrm{Ca}$ exchange selectivity coefficients are shown in Fig. 2. The trend observed on the data as a function of exchanger occupancy is in good agreement with the data taken from Thellier and Sposito (Thellier and Sposito, 1988; Thellier and Sposito, 1989b) under similar ionic strength conditions. Once again, one can observe considerable variability in the selectivity coefficient as a function of the exchanger composition. Note that the Na plus Ca occupancy never reaches $100 \%$ because of the presence of $\mathrm{K}$ in all of the experiments: the presence of $\mathrm{K}$ in solution and on the exchanger cannot be avoided due to its presence in the structural formula of illite and the weathering of the mineral. 
In the exchanger occupancy region, where $\mathrm{Na}$ or $\mathrm{Ca}$ account for almost all the cations present, the experimental points describe a bell-shaped curve. Similar observations are also made for $\mathrm{Na} / \mathrm{Mg}$ and $\mathrm{Ca} / \mathrm{Mg}$ exchange (not shown here, see Electronic Appendix 1). In the middle region (both $E_{N a}$ and $E_{C a}$ values are above 0.2 ), the exchange can be considered to be ideal with a constant selectivity coefficient value.

These new cation exchange data, together with data taken from the literature, illustrate the need to derive reliable parameters for calculating the exchange selectivity coefficients for illite. Two models are proposed in the following. The first is a multi-site approach and the second is a one-site approach, each of them having their own applicability domains.

\section{Multi-site modelling approach}

A multi-site modelling approach for cation exchange processes on illite has been shown to be successful in predicting $\mathrm{Cs}^{+}$sorption under various conditions of $\mathrm{pH}$ and ionic strength (e.g. BROUWER et al., 1983; PoINSSOT et al., 1999; ZACHARA et al., 2002; LiU et al., 2004) or to explain the variation in CEC measurements as a function of ionic strength with the ${ }^{22} \mathrm{Na}$ isotope dilution technique (BAEYENS and BRADBURY, 2004).

A similar approach was therefore adopted here in order to fit both the results of our experiments and the data obtained from literature. Data obtained in this study were first fitted with a two-site model, referred to as $\equiv \mathrm{Illa}^{-}$and $\equiv \mathrm{Illb}^{-}$, in agreement with the description of illite reactive surfaces with the presence of frayed edge and basal surface sites (e.g. PoINSSOT et al., 1999; ZACHARA et al., 2002).

Relative amounts of these two sites and Gaines and Thomas (e.g. Sposito, 1981) Na-K, Na$\mathrm{Ca}$ and $\mathrm{Na}-\mathrm{Mg}$ exchange selectivity coefficients were fitted concomitantly using the freely available parameter minimization PEST software (DOHERTY, 2004) in combination with PHREEQC v2.12 (PARKHURST and APPELO, 1999) and the Llnl.dat chemistry database for solute species. Solute concentrations were used as input data and the difference between 
measured and calculated equivalent fractions of $\mathrm{Na}, \mathrm{Ca}, \mathrm{K}$, and $\mathrm{Mg}$ on the exchanger were minimized by varying the fitting parameters given above. A second round of parameter minimization was then performed, where the difference between the measured and calculated natural logarithms of the Vanselow selectivity coefficients were minimized. This second round gave results identical to the first one. This second round of minimization was necessary to enable the comparison of the results of the two-site model with the results of the one-site model that was fitted only with the difference between measured and calculated natural logarithm of the Vanselow selectivity coefficients (see below, one-site model approach section).

Data from the literature were then simulated. The same selectivity coefficients were used, but the relative proportion of the sites was varied (while maintaining a constant total CEC) to capture the change in sorption behaviour as a function of the particle size distribution (or maximum particle size) considered. Only data at total normality $(\mathrm{TN})>0.005 \mathrm{~mol} / \mathrm{L}$ and with a complete description of the exchanger were used, i.e. excluding data where $\mathrm{K}$ occupancy is not available. The results of this fitting approach are given in Table 1 and Fig. 3.

The data of this study are reproduced by the model with quite low standard deviations on the difference between the measured and simulated equivalent fraction of each cation $\left(\sigma_{i}=\sqrt{\frac{m e a n-x_{i}}{N}}\right.$ where $x_{i}$ is the observable parameter, mean is the mean of this parameter and $N$ the number of scores): $\sigma_{\mathrm{XNa}}=0.052, \sigma_{\mathrm{XK}}=0.037, \sigma_{\mathrm{X} 2 \mathrm{Ca}}=0.054$ and $\sigma_{\mathrm{X} 2 \mathrm{Mg}}=0.061$. Data from the literature are reproduced with the following standard deviations on the difference between the measured and simulated equivalent fraction of each cation: $\sigma_{\mathrm{XNa}}=$ $0.066, \sigma_{\mathrm{XK}}=0.020, \sigma_{\mathrm{X} 2 \mathrm{Ca}}=0.073$ and $\sigma_{\mathrm{X} 2 \mathrm{Mg}}=0.057$ for data acquired at $\mathrm{TN}=0.005 \mathrm{~mol} / \mathrm{L}$, $\sigma_{\mathrm{XNa}}=0.166, \sigma_{\mathrm{XK}}=0.031, \sigma_{\mathrm{X} 2 \mathrm{Ca}}=0.178$ and $\sigma_{\mathrm{X} 2 \mathrm{Mg}}=0.077$ for data acquired at $\mathrm{TN}<0.005$ $\mathrm{mol} / \mathrm{L}$ down to $0.001 \mathrm{~mol} / \mathrm{L}$ (not shown), and $\sigma_{\mathrm{XNa}}=0.114, \sigma_{\mathrm{XK}}=0.009, \sigma_{\mathrm{X} 2 \mathrm{Ca}}=0.102$ and 
$\sigma_{\mathrm{X} 2 \mathrm{Mg}}=0.105$ for data acquired at $\mathrm{TN}>0.005$ up to $0.1 \mathrm{~mol} / \mathrm{L}$ (most of the data were given without $\mathrm{K}$ occupancy measurement, not shown). One notes that the data at $\mathrm{TN}<0.005 \mathrm{~mol} / \mathrm{L}$ are poorly reproduced as compared to the other data, especially for $\mathrm{Na}$ and $\mathrm{Ca}$. Incidentally, the change in selectivity coefficients for $\mathrm{Na}-\mathrm{Ca}$ exchange for example is very significant between $\mathrm{TN}=0.002 \mathrm{~mol} / \mathrm{L}$ and $\mathrm{TN}=0.005 \mathrm{~mol} / \mathrm{L}$ (see Fig. 4, $1 \log _{10}$ unit difference). Between $0.005 \mathrm{~mol} / \mathrm{L}$ and $0.0092 \mathrm{~mol} / \mathrm{L}$, the change in the selectivity coefficient value is within the uncertainty of the measurement. This behaviour explains why the two-site model selectivity coefficients derived at $0.005 \mathrm{~mol} / \mathrm{L}$ enable the results at $\mathrm{TN}>0.005 \mathrm{~mol} / \mathrm{L}$ to be predicted with good confidence, bearing in mind that most of the data obtained at these total normalities were obtained without K occupancy measurements.

Recently, Liu et al. (LIU et al., 2004) have proposed a two-site model explicitly taking into account the variation in the water activity in order to simulate the changes in Cs-Na and Cs-K exchange selectivity coefficients as a function of ionic strength. However, this method was applied to ionic strengths ranging from 0.01 to $5 \mathrm{~mol} / \mathrm{L}$, where the water activity value exhibits large variations. In the present study, water activity is nearly constant between 0.001 $\mathrm{mol} / \mathrm{L}$ and $0.01 \mathrm{~mol} / \mathrm{L}$. Moreover, in their model, one of the "driving forces" of the selectivity coefficient change as a function of ionic strength is also the difference in the number of moles of water per equivalent exchange capacity. This difference is high when a $\mathrm{Na}^{+}$ion is replaced by a $\mathrm{Cs}^{+}$ion because of the peculiar hydration properties of Cs at phyllosilicate surfaces. On the contrary, the difference when $\mathrm{Na}^{+}$is replaced by $\mathrm{Ca}^{2+}$ is expected to be small. Hence, no attempt was made to try to reproduce with the Liu et al. model the ionic strength effect that is observed in this study.

The modelling problem concerning data at low ionic strength could not have been fixed with the two-site model approach even by considering activity coefficients in the form of Davies or 
(Wateq) Debye-Hückel activity coefficients as proposed by the PHREEQC v2.12 capabilities. The Wateq Debye-Hückel activity coefficient is of the following form $\log _{10} \gamma_{i}=-\frac{A z_{i}^{2} \sqrt{I}}{1+B a_{i}^{0} \sqrt{I}}+b_{i} I$

where $\gamma_{i}$ is the activity of the exchanged species $i, A$ and $B$ are constants dependent only on temperature, $a_{i}^{0}$ and $b_{i}$ are exchanged species specific parameters, $I$ is the ionic strength and $z_{i}$ is the number of equivalents of exchanger in the exchange species $i$, e.g. 1 for $\mathrm{NaX}$ and 2 for $\mathrm{CaX}_{2}$ (PARKHURST and APPELO, 1999, pp 89). In the case of a $\mathrm{Na} \rightarrow \mathrm{Ca}$ exchange, one can evaluate the effect of Wateq Debye-Hückel activity coefficients by considering the variations - $\Delta \log _{10} K_{G T}(I)$ - they impose on the Gaines and Thomas selectivity coefficient as a function of the ionic strength:

$\Delta \log _{10} K_{G T}^{N a C a}(I)=2 A \sqrt{I} \times\left(\frac{1}{1+B a_{X N a}^{0} \sqrt{I}}-\frac{1}{1+B a_{X_{2} C a}^{0} \sqrt{I}}\right)+\left(b_{X_{2} C a}-2 b_{X N a}\right) \times I \quad$ Eq. 13

A judicious choice of parameter $b_{X 2 C a}$ and $b_{X N a}$ could help to fit the difference observed between the selectivity coefficient values obtained at ionic strength values 0.001 and 0.005 mol/L. However, these $b_{X 2 C a}$ and $b_{X N a}$ parameters are related to a linear behaviour as a function of ionic strength. This linear behaviour is not in agreement with the observation that shows a very sharp change between 0.003 and $0.005 \mathrm{~mol} / \mathrm{L}$ and almost no change below and above $0.005 \mathrm{~mol} / \mathrm{L}$. A sensibility test was performed on the influence of $a^{0}$ parameters on the $\Delta \log _{10} K_{G T}(I)$ value as a function of ionic strength. Considering two ionic strengths of 0.001 and $0.005 \mathrm{~mol} / \mathrm{L}$ together with $a^{0}$ parameters varying from 0 to 100 for $\mathrm{XNa}$ and $\mathrm{X}_{2} \mathrm{Ca}$, one obtains a maximum difference of $0.03 \log _{10}$ unit in $\Delta \log _{10} K_{G T}(I)$, which is clearly not sufficient to explain the experimental difference, the order of magnitude of which is about one $\log _{10}$ unit. 
In Table 1, one notes that only the Na-K exchange selectivity coefficient reaction has different values for the two sites $\equiv \mathrm{Illb}^{-}$and $\equiv \mathrm{Illa}^{-}$. For $\mathrm{Na}-\mathrm{Ca}$ and $\mathrm{Na}-\mathrm{Mg}$ exchange, the selectivity coefficient value remains constant and the variation in the selectivity coefficient as a function of the exchanger composition cannot be reproduced. Indeed, the bell-shaped curve observed for example for $\mathrm{Na} \rightarrow \mathrm{Ca}$ exchange, at a single ionic strength, cannot be reproduced by considering a multi-site model, whatever the number of sites considered in the calculation. Considering a population of sites with decreasing affinity for $\mathrm{Ca}$, one can easily show that these sites will be filled by order of affinity with $\mathrm{Ca}$ as a function of $\mathrm{Ca}$ occupancy of the exchanger, thereby creating a monotonic decrease in the global $\mathrm{Na} \rightarrow \mathrm{Ca}$ selectivity coefficient when the equivalent exchanged fraction of $\mathrm{Ca}$ increases. Note that it is well known that the use of a constant Gaines and Thomas selectivity coefficient leads to a Vanselow selectivity coefficient that varies slowly with the charge fraction of adsorbed divalent cations. However, this effect is not sufficient to model the sharp part of the curve at high bivalent cation exchanger loading (Fig. 2). Fig. 2 also shows the variation in the selectivity coefficient as a function of the equivalent fraction of exchanged calcium in $\mathrm{Na} / \mathrm{Ca}$ exchange experiments using various thermodynamic conventions: Vanselow, Gaines and Thomas, Gapon and Rothmund and Kornfeld (see Sposito, 1981 and Appelo C. A. J. and Parkhurst D. L. Calculating cation exchange with PHREEQC (Version 2), http://www.xs4all.nl/ appt/pub/). None of these representations enables a monotonic decrease in the selectivity coefficient as a function of the exchanger occupancy to be obtained, with the exception of the Rothmund and Kornfeld convention. However, this thermodynamic convention led to a large scattering between experimental points even for the points originating from the same experiment.

The increase in the $\mathrm{Na} \rightarrow \mathrm{Ca}$ (or $\mathrm{Na} \rightarrow \mathrm{Mg}$ ) selectivity coefficient concomitant to the increase in the $\mathrm{Ca}$ content on the exchanger signals the presence of a cooperative effect for exchanged Ca. We propose here two possible explanations for this effect. The first one relies on 
probabilities of exchange site combinations, given that $\mathrm{Ca}$ needs to exchange with two $\mathrm{Na}$ sites (Fig. 5).

The probabilities of the occurrence of configurations 1,2 and 3 are directly linked to the cation exchanger composition. Assuming a pure $\mathrm{Na} / \mathrm{Ca}$ system, and a random distribution of $\mathrm{Na}$ and $\mathrm{Ca}$ on the exchanger, one obtains the following probabilities of occurrence for the 3 situations given in Fig. 5:

$$
\begin{aligned}
& P_{1}=\left(\frac{E_{N a}}{E_{N a}+E_{C a} / 2}\right)^{2} \\
& P_{2}=2 \times\left(\frac{E_{N a}}{E_{N a}+E_{C a} / 2}\right) \times\left(\frac{E_{C a} / 2}{E_{N a}+E_{C a} / 2}\right) \\
& P_{3}=\left(\frac{E_{C a} / 2}{E_{N a}+E_{C a} / 2}\right)^{2}
\end{aligned}
$$

Now, assuming that configuration 2 is favoured thermodynamically compared to configuration 1 , it is expected that the value of the selectivity coefficient of the exchange process is correlated with the probability $\mathrm{P}_{2}$. In Fig. 6, it can be seen that the shape of the variation in the $\mathrm{P}_{2}$ probability value as a function of the Ca equivalent fraction is similar to that observed for the selectivity coefficient in $\mathrm{Na} / \mathrm{Ca}$ exchange experiments (Fig. 2).

A second explanation is linked to the flocculation behaviour of illite. Thellier and Sposito (THELlier and SpOsito, 1989a) have studied the effect of electrolyte concentration and exchangeable cations on the flocculation of Silver Hill Illite. As with montmorillonite (e.g. SCHRAMM and KWAK, 1982), they have shown that bivalent cations favour the flocculation of illite particles as compared to monovalent cations and that turbidity is developed gradually as the equivalent fraction of bivalent cations decreases from the 0.8 value. This effect of the bivalent cation on the flocculation of illite suspension is perfectly in agreement with an increase in the selectivity coefficient for $\mathrm{Na} \rightarrow \mathrm{Ca}$ exchange as a function of the increase in the exchanged $\mathrm{Ca}$, when considering the effect of stacking of the illite particles (Fig. 7). As 
already depicted by other authors for smectite monolayers (e.g. MCBRIDE, 1994, Fig. 7), the stacking of illite external basal surfaces might favour divalent and multivalent cations as compared to monovalent cations.

This last explanation would also be in agreement with the effect of ionic strength on the $\mathrm{Na} / \mathrm{Ca}$ and $\mathrm{Na} / \mathrm{Mg}$ selectivity coefficients. Fig. 8 shows the effect of the ionic strength on the percentage of light transmission through a suspension of $\mathrm{Na} / \mathrm{Ca}$ exchanged illite (data from THELLIER and Sposito, 1989a). The plotted experimental points correspond to conditions where equivalent bivalent cation fractions are $\sim 0.5$. Under these conditions, the solution composition is mainly dominated by $\mathrm{Na}^{+}$cations $(>97 \%)$. The light transmission is related to the flocculation (high percentages) or dispersion (low percentages) of the clay suspension (Thellier and Sposito, 1989a). One can not fail to note the sharp transition at approximately $4 \mathrm{mmol} / \mathrm{L}$, in agreement with the sharp variation observed for the $\mathrm{Na} / \mathrm{Ca}$ and $\mathrm{Na} / \mathrm{Mg}$ selectivity coefficient in the same ionic strength range value.

The stacking of illite particles then seems to have a marked effect on the selectivity coefficient for monovalent/bivalent cation exchange, but this cannot be taken into account in the above multi-site approach since the nature and the properties of the sites change as a function of the exchanger composition.

From this modelling result analysis, it appears that, concerning the prediction of the cation exchanger composition, the two-site model with constant Gaines and Thomas selectivity coefficients proposed in Table 1 can be used with good confidence for TN $>0.005 \mathrm{~mol} / \mathrm{L}$ and for exchanger occupancy as follows: $\mathrm{E}_{\mathrm{Na}} \in[0.1 ; 0.7], \mathrm{E}_{\mathrm{K}} \in[0.05 ; 1], \mathrm{E}_{\mathrm{Ca}} \in[0.25 ; 0.9], \mathrm{E}_{\mathrm{Mg}} \in$ $[0.25 ; 0.9]$. However, the ratio between the two types of site is needed. For natural systems, we think it likely that the values given in Table 1 for the literature data $(0.93$ and 0.07$)$ should be used in the absence of other information. The values for the present study were obtained on the $2 \mu \mathrm{m}$ fine fraction instead of the $115 \mu \mathrm{m}$ fraction for most other studies, a fraction that is 
more representative of a natural illite. The proportion of $\mathrm{K}^{+}$high affinity sites in the present study ( sites $\equiv \mathrm{Illb}^{-}=7-12 \%$ ) can be compared with the proportion of $\mathrm{Cs}^{+}$high affinity sites in other literature studies: $0.045 \%$ (Hanford sediment, LIU et al., 2004), $0.4+3 \sim 3.4 \%$ (Illite, COMANS et al., 1991), 1.5\% (Illite, POINSSOT et al., 1999). The proportion of $\mathrm{K}^{+}$high affinity sites is at least twice as high as the reported proportion of $\mathrm{Cs}^{+}$high affinity sites. This proportion can also be compared to the Type II sites and planar sites described by Baeyens and Bradbury (BAEYENS and BRADBURY, 2004) for $\mathrm{Na} \rightarrow \mathrm{Ca}+\mathrm{Mg}$ exchange: $20 \%$ and $80 \%$ respectively. The $\mathrm{Illb}^{-}$sites considered in the present model are then rather more similar to type II sites described in the literature than frayed edge sites whose influence is not visible in the Na-Ca-Mg-K exchange experiments, due to their low proportion. A third type of site should then certainly be added to our model. However, the data available in the literature do not enable its properties towards major cations $(\mathrm{Na}, \mathrm{Ca}, \mathrm{Mg}, \mathrm{K})$ to be calculated.

The exchange selectivity constants for $\mathrm{Na} \rightarrow \mathrm{Ca}$ exchange can also be compared with those given by Baeyens and Bradbury: $\log _{10} \mathrm{~K}_{\mathrm{GT}}(\mathrm{Na} \rightarrow \mathrm{Ca})=0.30$ for planar sites $(80 \%$ of the sites $)$ and $\log _{10} \mathrm{~K}_{\mathrm{GT}}(\mathrm{Na} \rightarrow \mathrm{Ca})=1.90$ for type II sites $(20 \%$ of the sites $)$. The values obtained in our study lie in the middle: $\log _{10} \mathrm{~K}_{\mathrm{GT}}(\mathrm{Na} \rightarrow \mathrm{Ca})=0.53$ for both sites. This could be explained by the fact that the values derived in (BAEYENS and BRADBURY, 2004) were not obtained from direct measurements of all the cations present on the exchanger and that $\mathrm{K}$ was never considered in their calculation. If $\mathrm{K}$ had been considered, their deduced amount of exchanged $\mathrm{Ca}$ would have been lowered and then the selectivity coefficient would have been lowered as well. The same type of problem may also have applied in the study carried out by Zachara et al. (ZACHARA et al., 2002). They treated their experiments as binary (e.g., Cs-Ca), when in fact $\mathrm{K}$ and even $\mathrm{Na}$ were almost certainly present, or in the case of Cs-Na, as binary when $\mathrm{K}, \mathrm{Mg}$, and $\mathrm{Ca}$ were present. This is a probable explanation for the underprediction of 
Cs retardation in column experiments using batch-derived data where no data on other cations (e.g. other than $\mathrm{Cs}$ and $\mathrm{Na}$ ) were available.

Note that for TN $>0.2 \mathrm{~mol} / \mathrm{L}$ in pure anionic chloride medium, the formation of chloridecation pairs on the illite surface could explain the deviation of the model result towards the high TN data available in Shainberg et al. (SHAINBERG et al., 1980): in these experiments the illite affinity for $\mathrm{Ca}$ increased when the $\mathrm{TN}$ increased. A Gaines and Thomas selectivity coefficient of $10^{3.5}$ for $\mathrm{Na} \rightarrow \mathrm{CaCl}^{+}$exchange reaction has been derived to fit these nine data points (not shown). This high selectivity coefficient value is in agreement with high selectivity coefficient values derived for chloride-cation pair exchange on montmorillonite surfaces (SPOSITO et al., 1983b; SPOSITO et al., 1983c; TOURNASSAT et al., 2004a; CHARLET and TOURNASSAT, 2005; FERRAGE et al., 2005).

As explained in the introduction, our interest lies primarily in the prediction of the solution composition as a function of the exchanger composition rather than conversely. It is possible to apply the procedure outlined in the introduction with a two-site model instead of a one-site model, provided that the ratio between the two types of site is known.

The prediction capability of the two-site model (inverse modelling) was then tested using the parameters listed in Table 1 for the literature data, keeping the total normality of the solution at the experimental value. All calculations were performed with PHREEQC v2.12 and the Llnl.dat associated database for solute species. When dealing with the literature data at TN $\geq$ $0.005 \mathrm{~mol} / \mathrm{L}$, the standard deviations on the difference between the experiment concentration values and the modelled concentration values in $\log _{10}$ units are as follows: $\sigma_{\left[\mathrm{Na}^{+}\right]}=0.32, \sigma_{[\mathrm{K}+]}$ $=1.31, \sigma_{[\mathrm{Ca} 2+]}=0.43$ and $\sigma_{[\mathrm{Mg} 2+]}=0.34$. Surprisingly, this standard deviation is higher for $\mathrm{K}^{+}$ concentration predictions than for the other cations despite the fact that the standard deviation on the difference between the measured and simulated equivalent fraction of the model was the lowest for $\mathrm{K}$ exchanger occupancy in the direct modelling. Most of this deviation 
originates from a "Ca-Mg" exchange experiment in THELliER and SpOSITO, 1988, with a low $\mathrm{K}$ content. If this experiment is neglected, the standard deviation on the difference between the experimental concentration values and the modelled concentration values in $\log _{10}$ units becomes $\sigma_{[\mathrm{K}+]}=0.63$. When considering the total dataset from the literature, standard deviations are similar: $\sigma_{[\mathrm{Na}+]}=0.30, \sigma_{[\mathrm{K}+]}=1.16(0.61$ without the Ca-Mg experiment cited above), $\sigma_{[\mathrm{Ca} 2+]}=0.64$ and $\sigma_{[\mathrm{Mg} 2+]}=0.51$.

Hence, based on the experimental cation exchange occupancy and the two-site model presented here, the potassium concentration can be calculated with an accuracy of $\pm \sim 1 \log _{10}$ unit. Other elements are calculated with an accuracy of $\pm \sim 0.3-0.6 \log _{10}$ unit. The concentration prediction capability of the present two-site model is then not very accurate, especially for potassium whose concentration can be underestimated or overestimated by a factor of ten. On the contrary, the direct modelling of cation exchange occupancy leads to rather good results as long as one remains within the range of the site occupancy given previously. One should note that the sites proportion is the key factor governing the success of the model.

\section{One-site modelling approach}

The uncertainty on the concentration prediction capability of the two-site model presented above leads us to model the data in a different way: the changes in selectivity coefficient are interpreted here as a continuous change in surface species activity coefficient. The use of a one-site model for cation-exchange on illite represents a departure from the approach used in all recent studies. Although questionable from a theoretical point of view, it will be shown in the following that this approach allows a better concentration prediction capability than a twosite model with constant selectivity coefficients.

Given the multi-site microscopic reality of the exchange process on illite surfaces, it is unlikely that the following proposed one-site method is thermodynamically correct. Instead, it 
should be regarded as an empirical method to approach the exchange selectivity coefficients as a function of exchanger composition and ionic strength.

\section{Activity coefficients and exchange equilibrium constants calculation in binary}

exchanges. The calculation method presented here concerns only monovalent and divalent species. Instead of using a generic term for chemical species, we have chosen to present the calculations with $\mathrm{Na}, \mathrm{K}$ and $\mathrm{Ca}$ as example cases. More generic representations of these calculations can be found in for example Chu and Sposito (CHU and SPOSITO, 1981).

Let us consider the Ca-K divalent-monovalent exchange reaction:

$\mathrm{CaX}_{2}+2 \mathrm{~K}^{+} \Leftrightarrow \mathrm{Ca}^{2+}+2 \mathrm{KX}$

Reaction 4

The constant associated with this exchange is:

$K^{\mathrm{Ca} / K}=\frac{\left\{\mathrm{Ca}^{2+}\right\} \times\{K X\}^{2}}{\left\{\mathrm{CaX}_{2}\right\} \times\left\{K^{+}\right\}^{2}}$

The surface species activities are given by the following relationship

$\{K X\}=N_{K} \times f_{K}^{C a K}$

Eq. 18

where $N_{K}$ is the molar fraction of the surface species $K X$ (in this particular case $N_{K}=\frac{[K X]}{[K X]+\left[\mathrm{CaX}_{2}\right]}$, and $f_{K}^{C a K}$ is the activity coefficient of the surface species $K X$ that depends on the exchanger composition. By introducing the Vanselow selectivity coefficient (VANSELOW, 1932), one derives

$K^{C a / K}=K_{v}^{C a / K} \times \frac{f_{K}^{C a K^{2}}}{f_{C a}^{C a K}}$.

At constant $\mathrm{T}$ and $\mathrm{P}$, and considering no variation in the surface water activity, the GibbsDuhem equation, applied to the exchanger phase only, gives (SPOSITO, 1989, see Electronic Appendix 2 for more details): 
$2 \times \ln f_{K}^{C a K}=-E_{C a} \times \ln K_{v}^{C a / K}+\int_{0}^{E_{C a}} \ln K_{v}^{C a / K} \times d E_{C a}^{\prime}$

$\ln f_{C a}^{C a K}=E_{K} \times \ln K_{v}^{C a / K}-\int_{0}^{E_{K}} \ln K_{v}^{C a / K} d E_{K}^{\prime}$

$\ln K^{C a / K}=\int_{0}^{1} \ln K_{v}^{C a / K} d E_{K}^{\prime}=-\int_{0}^{1} \ln K_{v}^{C a / K} d E_{C a}^{\prime}$

Eq. 22

Similar equations are obtained in the case of a homovalent exchange (e.g. $\mathrm{Na} / \mathrm{K}$ or $\mathrm{Ca} / \mathrm{Mg}$, See Electronic Appendix 2)

Eqs. 20 to 22 can be evaluated by finding an expression that relates $\ln K_{v}$ and the exchanger composition (SPOSITO, 1989; AgBENIN and YAKUBU, 2006). The curves obtained in this study for $\mathrm{Na} / \mathrm{Ca}$ exchange (in the presence of a minor presence of $\mathrm{K}^{+}$on the exchanger) are very sharp near to the 0 and 1 values for $E_{C a}$ or $E_{N a}$ respectively (Fig. 2). For practical reasons, it is then necessary to introduce into the $\ln K_{v}^{C a / K}$ equation a term that is easily integrated and that can account for the sharp shapes of the curves. It was found that exponential terms were far more efficient than high order polynomial terms because exponential terms do not introduce oscillations of the fitting curve in the central region of the curve, where $E_{\mathrm{Ca}}$ or $E_{\mathrm{Na}}$ stand between 0.3 and 0.6

By considering the following equation:

$\ln K_{v}^{C a / K}={ }^{0} a_{C a K}+{ }^{1} a_{C a K} E_{K}+{ }^{2} a_{C a K} E_{K}{ }^{2}+{ }^{3} a_{C a K} E_{K}{ }^{3}+B_{C a K} \times e^{-b_{C a K} E_{K}}+C_{C a K} \times e^{-c_{C a K}\left(1-E_{K}\right)}$

Eq. 23

and by applying it to other binary exchanges, it should be possible to fit reasonably well even very complicated shaped $\ln K_{v}$ curves.

One can then obtain: 
$\ln K^{\mathrm{Ca} / K}={ }^{0} a_{\mathrm{CaK}}+\frac{{ }^{1} a_{C a K}}{2}+\frac{{ }^{2} a_{C a K}}{3}+\frac{{ }^{3} a_{C a K}}{4}+\frac{B_{C a K}}{b_{C a K}} \times\left(1-e^{-b_{C a K}}\right)+\frac{C_{C a K}}{c_{C a K}} \times\left(1-e^{-c_{C a K}}\right)$

Eq. 24

$$
\begin{aligned}
& \ln f_{C a}^{C a K}= \\
& =\frac{{ }^{1} a_{C a K} E_{K}{ }^{2}}{2}+2 \times \frac{{ }^{2} a_{C a K} E_{K}{ }^{3}}{3}+3 \times \frac{{ }^{3} a_{C a K} E_{K}{ }^{4}}{4} \\
& \quad+e^{-b_{C a K} E_{K}} \times\left(E_{K} \times B_{C a K}+\frac{B_{C a K}}{b_{C a K}}\right)+e^{-c_{C a K}\left(1-E_{K}\right)} \times\left(E_{K} \times C_{C a K}-\frac{C_{C a K}}{c_{C a K}}\right)-\frac{B_{C a K}}{b_{C a K}}+\frac{C_{C a K} \times e^{-c_{C a K}}}{c_{C a K}}
\end{aligned}
$$

Eq. 25

$$
\begin{aligned}
& \ln f_{K}^{C a K}= \\
& \left(\begin{array}{l}
\left.\frac{1}{4} E_{C a}{ }^{2} \times\left({ }^{1} a_{C a K}+2 \times^{2} a_{C a K}+3 \times^{3} a_{C a K}\right)-\frac{1}{6} E_{C a}^{3} \times\left(2 \times^{2} a_{C a K}+6 \times^{3} a_{C a K}\right)+\frac{1}{8} E_{C a}{ }^{4} \times 3 \times{ }^{3} a_{C a K}\right) \\
+\frac{1}{2} \times\left(\begin{array}{l}
\left.\frac{B_{C a K}}{b_{C a K}} \times\left(-e^{-b_{C a K}}\right)+e^{-b_{C a K}\left(1-E_{C a}\right)} \times B_{C a K} \times\left(1-E_{C a}\right)+\frac{\left(1-b_{C a K}\right)}{b_{C a K}}\right) \\
+\frac{C_{C a K}}{c_{C a K}}+e^{-c_{C a K}\left(E_{C a}\right)} \times C_{C a K} \times\left(\left(1-E_{C a}\right)-\frac{\left(1+c_{C a K}\right)}{c_{C a K}}\right)
\end{array}\right)
\end{array}\right)
\end{aligned}
$$

Eq. 26

The same type of equations are obtained for $\ln K^{N a / K}, \ln f_{N a}$ and $\ln f_{K}$ (see Electronic Appendix 2 for more details).

Given the above formula, the activity coefficient of surface species should be calculated on the basis of the $K_{v}$ data given as a function of the exchanger composition only. However, based on literature data, we have shown that the ionic strength has an influence on the selectivity constant value. This information partially invalidates the above approach. The effect of ionic strength is likely to originate in changes in the electrostatic field near to the surface, creating conditions favourable or not to the aggregation of particles (see discussion in the multi-site modelling approach section). Considering the role of ionic strength, Eq. 19 must be rewritten: 


$$
K^{C a / K}=K_{v}^{C a / K} \times \frac{g_{K}{ }^{2}}{g_{C a}}
$$

with $g$ a function depending on the exchanger composition and the ionic strength. This means that all of the polynomial and exponential coefficients given in Eqs. 24 to 26 are a function of ionic strength. It is not now conceivable to define such a function for all of the necessary parameters. However, as a simplification, one can assume that: $g=f \times h$ where $h$ is a function of ionic strength $(I)$ only. Defining the reference state at $\mathrm{I}=0$, the $h$ function should converge to 1 when I converges to 0 . By analyzing data from Thellier and Sposito (THELLIER and Sposito, 1989b), one should also note that the logarithm of $h$ function ratios converge to one other limit at $\mathrm{I} \sim 0.004-0.005$, then describing a sigmoid curve, in correlation with the flocculation behaviour of illite suspension (THELLIER and SPOSITO, 1989a). They have also shown that this flocculation behaviour is a function of the bivalent cation exchanged fraction. However, no attempt was made to calculate explicitly all $h$ functions as a function of their relative cations. The logarithm of $h$ function ratios were approached with a complementary error function $(e r f c)$ with the form of:

$$
\ln h_{K}^{\mathrm{NaK}}-\ln h_{\mathrm{Na}}^{\mathrm{NaK}}=\alpha_{\mathrm{NaK}} \times \operatorname{erfc}\left(\beta_{\mathrm{NaK}}-\frac{I}{\gamma_{\mathrm{NaK}}}\right),
$$

for monovalent / monovalent interactions or

$$
2 \times \ln h_{K}^{C a K}-\ln h_{C a}^{C a K}=\alpha_{C a K} \times \operatorname{erfc}\left(\beta_{C a K}-\frac{I}{\gamma_{C a K}}\right) .
$$

for monovalent / divalent interactions.

These functions must be considered as a very convenient way of trapping the ionic strength effect. The Na-K, Ca-Na, and Mg-Na systems were described with such functions leading to nine new fitting parameters and allowing other systems (Ca-Mg, Ca-K and $\mathrm{Mg}-\mathrm{K})$ to be described by combinations of the former ones. 
exchanges. Chu and Sposito (CHU and SPOSITO, 1981) have demonstrated that ternary exchange thermodynamic parameters cannot be deduced from binary parameters only. However, we decided voluntary to oversimplify our system given (i) that it already contains a lot of fitting parameters and (ii) that a one-site true thermodynamic description is certainly not possible due to the multi-site nature of the exchange process.

We assume here firstly that the activity coefficients for $\mathrm{Na}, \mathrm{K}, \mathrm{Ca}$ and $\mathrm{Mg}$ exchanged species in a multicomponent exchange can be approximated from the individual binary contributions without crossing terms, i.e.:

$$
\begin{array}{ll}
\ln f_{\mathrm{Ca}}^{\mathrm{NaKMgCa}}=\ln f_{\mathrm{Ca}}^{\mathrm{CaK}}+\ln f_{\mathrm{Ca}}^{\mathrm{CaNa}}+\ln f_{\mathrm{Ca}}^{\mathrm{CaMg}} \quad \text { Eq. } 30
\end{array}
$$

However, in a $\mathrm{Ca}-\mathrm{Mg}$ exchange experiment in the presence of $\mathrm{Na}$ and $\mathrm{K}$, one can note that the $\ln K_{v}{ }^{C a / K}$ value depends only on $E_{N a}$ and $E_{K}$, not on the ratio between $E_{M g}$ and $E_{C a}$ (Fig. 9). This means that $\mathrm{Ca}$ and $\mathrm{Mg}$ have a joint similar effect on the $\mathrm{Ca}-\mathrm{K}$ exchange selectivity coefficient. This effect is taken into account by considering the following combination:

$\ln f_{K}^{\mathrm{CaMgNaK}}=\ln f_{K}^{\mathrm{NaK}}+\ln f_{K}^{\mathrm{CaMgK}}$

where $\ln f_{K}^{C a M g K}$ is the weighted mean of $\ln f_{K}^{C a N a}$ and $\ln f_{K}^{C a M g}$ (see Electronic Appendix 2 for the full formula).

With this approach we then obtained four mathematical expressions for the activity coefficients of exchanged $\mathrm{Na}, \mathrm{K}, \mathrm{Ca}$ and $\mathrm{Mg}$ :

$$
\begin{array}{lrl}
\ln f_{K}^{\mathrm{CaMgNaK}}=\ln f_{K}^{\mathrm{NaK}}+\ln f_{K}^{\mathrm{CaMgK}} & \text { Eq. } 32 \\
\ln f_{\mathrm{Na}}^{\mathrm{CaMgKNa}}=\ln f_{\mathrm{Na}}^{\mathrm{NaK}}+\ln f_{\mathrm{Na}}^{\mathrm{CaMgNa}} & \text { Eq. } 33 \\
\ln f_{\mathrm{Ca}}^{\mathrm{MgNNaCa}}=\ln f_{\mathrm{Ca}}^{\mathrm{CaK}}+\ln f_{\mathrm{Ca}}^{\mathrm{CaNa}}+\ln f_{\mathrm{Ca}}^{\mathrm{CaMg}} & \text { Eq. } 34 \\
\ln f_{\mathrm{Mg}}^{\mathrm{CaKNaMg}}=\ln f_{\mathrm{Mg}}^{\mathrm{MgK}}+\ln f_{\mathrm{Mg}}^{\mathrm{MgNa}}+\ln f_{\mathrm{Mg}}^{\mathrm{CaMg}} & \text { Eq. } 35
\end{array}
$$


The efficiency of the model to capture the variations in the selectivity coefficients as a function of exchanger composition and ionic strength was then tested.

\section{Modelling of experimental and literature results}

Equilibrium constants and activity coefficients were obtained from the polynomial and exponential coefficients as described above. The fitting approach also takes into consideration one additional constraint concerning the exchange equilibrium constants consistency, which is the constant additivity, i.e. for a $\mathrm{Ca} / \mathrm{Na} / \mathrm{K}$ system:

$\ln K^{\mathrm{Ca} / \mathrm{Na}}+2 \times \ln K^{\mathrm{Na} / K}=\ln K^{\mathrm{Ca} / K}$

Eq. 36

The least square fitting approach of these parameters was broken down into several steps:

- Firstly, only data at $\mathrm{TN}=0.005 \mathrm{~mol} / \mathrm{L}$ were considered and the $a, B, b, C$ and $c$ parameters were fitted for $\mathrm{Na}, \mathrm{K}$ and $\mathrm{Ca}$, considering that the parameters for $\mathrm{Mg}$ were identical to Ca.

- Secondly, the Mg parameters were fitted together with the former parameters obtained for $\mathrm{Na}, \mathrm{K}$ and $\mathrm{Ca}$.

- Finally, the $\alpha, \beta$ and $\gamma$ parameters, concerning ionic strength effects, were fitted for the system $\mathrm{Ca}-\mathrm{Na}, \mathrm{Na}-\mathrm{K}$ and $\mathrm{Mg}-\mathrm{Na}$ separately before a last fitting round concerning all of the parameters.

This approach was reiterated until the fit was found to be satisfactory. Note that the fitted systems are always multi-component (most of them are quaternary systems) and thereby highly non-linear. Reiteration of the fitting procedure was then necessary. The parameters obtained from this regression analysis are given in Tables 2 and 3. Of course, we are aware 
that these coefficients are not definitive and certainly not the best solutions, given the high number of fitting parameters. Complementary experiments are needed to better constrain them, especially $\mathrm{Ca}-\mathrm{K}$ and $\mathrm{Mg}-\mathrm{K}$ binary exchanges at different ionic strengths and with data at high $\mathrm{K}$ surface coverage. The result of the fit is presented in Figs. 10 and 11 together with standard deviation of the simulation as compared to the experimental data.

The concentration prediction capability of the model was then tested using the same procedure as that used for the two-site model: the TN was kept at the experimental TN and the selectivity coefficients were calculated as a function of the normality and the exchanger composition. A Gaines and Thomas convention was used because the calculations were performed with PHREEQC v2.12. Gaines and Thomas selectivity coefficients were recalculated according to Eq. 11.

Results are shown in Fig. 12 together with the standard deviation of the simulation as compared to the experimental data. Note that the $\mathrm{K}$ concentrations in the $\mathrm{Na}-\mathrm{Ca}$ and $\mathrm{Na}-\mathrm{Mg}$ exchange experiment of the present study have been discarded, as for the presentation of the two-site model result. On the contrary, results concerning $\mathrm{Na}, \mathrm{Ca}$ and $\mathrm{Mg}$ concentrations of the present study are also presented.

Significant deviations are observed mainly for $\mathrm{Mg}$ concentrations, but the precision of the concentration prediction is far better than the precision obtained with the two-site model. For the two-site model we obtained the following standard deviations on the difference between the experiment concentration values and the modelled concentration values in $\log _{10}$ units $\sigma_{[\mathrm{Na}+]}=0.30, \sigma_{[\mathrm{K}+]}=1.16, \sigma_{[\mathrm{Ca} 2+]}=0.64$ and $\sigma_{[\mathrm{Mg} 2+]}=0.51$. With the present one-site model, one obtains: $\sigma_{[\mathrm{Na}+]}=0.13, \sigma_{[\mathrm{K}+]}=0.10, \sigma_{[\mathrm{Ca} 2+]}=0.30$ and $\sigma_{[\mathrm{Mg} 2+]}=0.45$, highlighting the improvement of the fit, especially for the potassium concentration prediction. Even points that lack data measurement for $\mathrm{K}^{+}$in solution and on the exchanger are well predicted (data from ShainBerg et al., 1980; Sposito and LeVeSQue, 1985). The proposed one-site model thereby 
makes it possible to recover the concentrations of the major cations in a solution in contact with an illite whose exchanger composition is known.

\section{Application to natural and engineered systems}

Natural systems with a clay fraction constituted only by illite are not common. Here we consider the example of illite rich layers in the Callovian-Oxfordian formation for the calculation of exchanger selectivity coefficients towards $\mathrm{Na}, \mathrm{Ca}, \mathrm{Mg}$ and $\mathrm{K}$. Data on exchanger composition and ionic strength were obtained from Gaucher et al. (GAUCHER et al., 2004) and are given in Table 4. Selectivity coefficients in the Vanselow convention were calculated using the model described in this paper (Table 4). Associated concentrations in porewater can then be calculated, provided the total normality is known and the sulphate and chloride anion proportions are known. In agreement with Gaucher et al. (GAUCHER et al., Accepted), we considered a solute $\mathrm{S}(+6) / \mathrm{Cl}(-1)$ equivalent ratio of 2 as an approximation. The

results of the calculation (Table 4) shows that the porewater composition is likely to be constituted mainly of $\mathrm{Na}$ cations ( $~ 54 \%$ of the cation equivalent concentration) then $\mathrm{Ca}$ cations $(\sim 30 \%), \mathrm{Mg}$ cations $(\sim 14 \%), \mathrm{K}$ cations representing less than $2 \%$ of the cation equivalent charge with concentrations ranging from 1.4 to $2 \mathrm{mmol} / \mathrm{L}$. Future porewater extraction results from the Bure underground research laboratory will help to verify the accuracy of the model.

\section{Conclusions}

We have shown that our one-site model considering the ionic strength effect and variations in the surface species activity coefficients is efficient for the determination of water major cation 
composition for a wide range of exchanger compositions. For natural systems, this model still needs to be refined in order to consider the presence of smectite and illite/smectite rather than pure illite. Moreover, the compaction effect deserves further study as a similar effect of compaction is expected as compared to that of ionic strength. It is obvious that this model will be the most efficient for illite exhibiting the same shape parameters, provided the proportions of the different types of sites are controlled by the morphology of the particles. As a matter of interest, the data fitted here concern only Silver Hill Illite (Imt-1 and 2, Montana) and Fithian Illite (Illinois).

For the prediction of the exchanger composition as a function of the solution cation concentrations, a multi-site model as presented in the first part of this paper is certainly more appropriate, even if some features of the exchange isotherm, e.g. the "bell-shaped" aspect of the curve, cannot be predicted. Ideally, we believe that the two approaches should be combined in order to take into account the peculiar behaviour of $\mathrm{Cs}$ or $\mathrm{K}$ cations on high affinity sites such as frayed edge sites.

\section{Acknowledgements}

This research was funded by the French National Radioactive Waste Management Agency (ANDRA) and the French Geological Survey (BRGM) in the framework of the BRGMANDRA scientific partnership (THERMOAR project under the coordination of Dr. E. Jacquot and Dr. E. Gaucher). H.G. acknowledges ANDRA for her Ph.D. financial support, under the supervision of Dr. N. Michau. Dr. C.A.J. Appelo, two anonymous reviewers and Pr. Sposito, Associate Editor, are gratefully acknowledged for their constructive comments in reviewing this paper. 


\section{References}

Agbenin J. O. and Yakubu S. (2006) Potassium-calcium and potassium-magnesium exchange equilibria in an acid savanna soil from northern Nigeria. Geoderma In Press, Corrected Proof.

Baeyens B. and Bradbury M. (2004) Cation exchange capacity measurements on illite using the sodium and cesium isotope dilution technique: effects of the index cation, electrolyte concentration and competition: modeling. Clays and Clay Minerals 52, 421-431.

Bethke C. M. (1996) Geochemical reaction modeling. Oxford University Press.

Bradbury M. H. and Baeyens B. (1998) A Physicochemical characterisation and geochemical modelling approach for determining porewater chemistries in argillaceous rocks. Geochimica et Cosmochimica Acta 62, 783-795.

Brouwer E., Baeyens B., Maes A., and Cremers A. (1983) Cesium and Rubidium ion equilibria in illite clay. Journal of Physical Chemistry 87, 1213-1219.

Charlet L. and Tournassat C. (2005) Fe(II)-Na(I)-Ca(II) cation exchange on montmorillonite in chloride medium; evidence for preferential clay adsorption of chloride - metal ion pairs in seawater. Aquatic Geochemistry 11, 115-137.

Chu S. Y. and Sposito G. (1981) The thermodynamics of ternary cation exchange systems and the subregular model. Soil Science Society of America Journal 45, 1084-1089.

Ciesielski H. and Sterckeman T. (1997) Determination of cation exchange capacity and exchangeable cations in soils by means of cobalt hexamine trichloride. Effects of experimental conditions. Agronomie 17, 1-7.

Comans R. N. J., Haller M., and De Preter P. (1991) Sorption of cesium on illite: Nonequilibrium behaviour and reversibility. Geochimica et Cosmochimica Acta 55, 433440.

Doherty J. (2004) PEST Model-independent parameter estimation (ed. W. N. Computing).

Ferrage E., Tournassat C., Rinnert E., Charlet L., and Lanson B. (2005) Evidence for calciumchloride ion pairs in the interlayer of montmorillonite and implications on hydration state. A XRD profile modelling approach. Clays and Clay Minerals 53, 348-361.

Fletcher P. and Sposito G. (1989) The chemical modeling of clay/electrolyte interactions for montmorillonite. Clay Minerals 24, 375-391.

Gaucher E., Robelin C., Matray J. M., Negrel G., Gros Y., Heitz J. F., Vinsot A., Rebours H., Cassabagnere A., and Bouchet A. (2004) ANDRA underground research laboratory: Interpretation of the mineralogical and geochemical data acquired in the CallovianOxfordian Formation by investigative drilling. Physics and chemistry of the earth 29, $55-77$.

Gaucher E. C., Altmann S., Blanc P., Bardot F., Jacquot E., Lassin A., Negrel G., Braibant G., Breeze D., Crouzet C., and Gautier A. (Accepted) Porewater chemistry simulation of the Callovian-Oxfordian Formation. Compte-Rendu Geosciences.

Jensen H. E. (1973) Potassium - calcium exchange equilibria on a montmorillonite and a kaolinite clay. Agrochimica 17, 181-190.

Liu C., Zachara J. M., and Smith S. C. (2004) A cation exchange model to describe $\mathrm{Cs}^{+}$ sorption at high ionic strength in subsurface sediments at Hanford site, USA. Journal of Contaminant Hydrology 68, 217-238.

McBride M. B. (1994) Environmental Chemistry of Soils. Oxford University Press. 
Parkhurst D. L. and Appelo C. A. J. (1999) User's guide to phreeqc - a computer program for speciation, batch-reaction, one-dimensional transport, and inverse geochemical calculations, Report No. 99-4259.

Pearson F. J., Arcos D., Boisson J.-Y., Fernandez A. M., Gäbler H.-E., Gaucher E., Gautschi A., Griffault L., Hernan P., and Waber H. N. (2003) Mont Terri project Geochemistry of water in the Opalinus clay formation at the Mont Terri Rock Laboratory. In Geology Series, Vol. 5 (ed. F.O.W.G.).

Poinssot C., Baeyens B., and Bradbury M. H. (1999) Experimental and modelling studies of caesium sorption on illite. Geochimica et Cosmochimica Acta 63, 3217-3227.

Schramm L. L. and Kwak J. C. T. (1982) Influence of exchangeable cation composition on the size and shape of montmorillonite particles in dilute suspension. Clays and Clay Minerals 30, 40-48.

Shainberg I., Oster J. D., and Wood J. D. (1980) Sodium/calcium exchange in montmorillonite and Illite suspension. Soil Science Society of America Journal 44, 960-964.

Sposito G. (1981) The thermodynamics of soil solution. Oxford University Press.

Sposito G. (1989) The chemistry of soils. Oxford University Press.

Sposito G., Holtzclaw K. M., Charlet L., Jouany C., and Page A. L. (1983a) Sodium-calcium and sodium-magnesium exchange on Wyoming bentonite in perchlorate and chloride background ionic media. Soil Science Society of America Journal 47, 51-56.

Sposito G., Holtzclaw K. M., Jouany C., and Charlet L. (1983b) Cation selectivity in sodiumcalcium, sodium-magnesium, and calcium-magnesium exchange on Wyoming bentonite at 298 K. Soil Science Society of America Journal 47, 917-921.

Sposito G., Jouany C., Holtzclaw K. M., and LeVesque C. S. (1983c) Calcium-Magnesium exchange on Wyoming bentonite in the presence of adsorbed sodium. Soil Science Society of America Journal 47, 1081-1085.

Sposito G. and LeVesque C. S. (1985) Sodium-calcium-magnesium exchange on Silver Hill Illite. Soil Science Society of America Journal 49, 1153-1159.

Steefel C. I. (2001) GIMRT, version 1.2: Software for modeling multicomponent, multidimensional reactive transport. User's Guide, Report No. UCRL-MA-143182.

Thellier C. and Sposito G. (1988) Quaternary cation exchange on Silver Hill illite. Soil Science Society of America Journal 52, 979-985.

Thellier C. and Sposito G. (1989a) Influence of electrolyte concentration and exchangeable cations on the flocculation of Silver Hill illite. Soil Science Society of America Journal 53, 711-715.

Thellier C. and Sposito G. (1989b) Influence of electrolyte concentration on quaternary exchange by Silver Hill illite. Soil Science Society of America Journal 53, 705-711.

Thellier C., Sposito G., and Holtzclaw K. M. (1992) Proton effects on quaternary cation exchange and flocculation of Silver Hill illite. Soil Science Society of America Journal 56, 427-433.

Tournassat C., Ferrage E., Poinsignon C., and Charlet L. (2004a) The titration of clay minerals. Part II. Structural-based model and implications for clay reactivity. Journal of Colloid and Interface Science 273, 234-246.

Tournassat C., Greneche J. M., Tisserand D., and Charlet L. (2004b) The titration of clay minerals. Part I. Discontinuous backtitration technique combined to CEC measurements. Journal of Colloid and Interface Science 273, 224-233.

Vanselow A. P. (1932) Equilibria of the base-exchange reaction of bentonites, permutites, Soil colloids and zeolites. Soil Science 33, 95-113. 
Zachara J. M., Smith S. C., Liu C., McKinley J. P., Serne R. J., and Gassman P. L. (2002) Sorption of $\mathrm{Cs}+$ to micaceous subsurface sediments from the Hanford site, USA. Geochimica et Cosmochimica Acta 66, 193-211. 


\section{Tables}

Table 1. Two-site model parameters for the modelling of $\mathrm{Na}-\mathrm{K}-\mathrm{Ca}-\mathrm{Mg}$ exchange experiments. Data from the literature are taken from: Shainberg et al., 1980; Sposito and LeVesQue, 1985; THellier and Sposito, 1988; THellier and Sposito, 1989b; THELlier et al., 1992.

$$
\equiv \mathrm{Illa}^{-} \quad \equiv \mathrm{Illb}^{-}
$$

This study

Literature data

This study

Literature data

Site proportions

\begin{tabular}{llll}
\hline 0.88 & 0.93 & 0.12 & 0.07
\end{tabular}

Exchange selectivity coefficients

\begin{tabular}{lcc}
\hline $\mathrm{Na}-\mathrm{K}$ & 0.52 & 6.7 \\
$\mathrm{Na}-\mathrm{Ca}$ & 0.53 & 0.53 \\
$\mathrm{Na}-\mathrm{Mg}$ & 0.55 & 0.55 \\
\hline
\end{tabular}


Table 2. Ionic strength coefficients (Eqs. 28 and 29).

\begin{tabular}{cccc}
\hline & $\mathrm{Na} / \mathrm{K}$ & $\mathrm{Ca} / \mathrm{Na}$ & $\mathrm{Mg} / \mathrm{Na}$ \\
\hline$\alpha$ & 0.43 & -0.8 & -1.1 \\
$\beta$ & 17.58 & 17.58 & 17.58 \\
$\chi$ & $1.915 \times 10^{-4}$ & $1.915 \times 10^{-4}$ & $1.915 \times 10^{-4}$ \\
\hline
\end{tabular}


Table 3. Polynomial and exponential coefficients obtained for $\mathrm{Ca} / \mathrm{K}, \mathrm{Ca} / \mathrm{Na}, \mathrm{Na} / \mathrm{K}, \mathrm{Mg} / \mathrm{Ca}$, $\mathrm{Mg} / \mathrm{Na}$ and $\mathrm{Mg} / \mathrm{K}$ exchange reactions, together with calculated thermodynamic exchange reaction equilibrium constants.

\begin{tabular}{lclll}
\hline \multicolumn{2}{l}{ Ca/K exchange } & \multicolumn{3}{l}{} \\
\hline \multicolumn{2}{l}{ Polynomial coefficients } & \multicolumn{2}{l}{ Exponential coefficients } & $\ln K^{\mathrm{CaK}}$ \\
${ }^{0} a_{\mathrm{CaK}}$ & 1.43 & $B_{\mathrm{CaK}}$ & 7.39 & \\
${ }^{1} a_{\mathrm{CaK}}$ & 0.293 & $b_{\mathrm{CaK}}$ & 1.055 & 6.13 \\
${ }^{2} a_{\mathrm{CaK}}$ & 0.162 & $C_{\mathrm{CaK}}$ & -0.837 & \\
${ }^{3} a_{\mathrm{CaK}}$ & 0.222 & $c_{\mathrm{CaK}}$ & 7.078 & \\
\hline
\end{tabular}

\section{$\mathrm{Ca} / \mathrm{Na}$ exchange}

Polynomial coefficients Exponential coefficients $\ln K^{\mathrm{CaNa}}$

\begin{tabular}{lllll}
${ }^{0} a_{\mathrm{CaNa}}$ & 1.34 & $B_{\mathrm{CaNa}}$ & 254 & \\
${ }^{1} a_{\mathrm{CaNa}}$ & -0.342 & $b_{\mathrm{CaNa}}$ & 58.77 & 6.08 \\
${ }^{2} a_{\mathrm{CaNa}}$ & -0.816 & $C_{\mathrm{CaNa}}$ & -0.026 & \\
${ }^{3} a_{\mathrm{CaNa}}$ & 3.542 & $c_{\mathrm{CaNa}}$ & 0.010 & \\
\hline
\end{tabular}

\section{$\mathrm{Na} / \mathrm{K}$ exchange}

Polynomial coefficients Exponential coefficients $\ln K^{\mathrm{NaK}}$

\begin{tabular}{lllll}
${ }^{0} a_{\mathrm{CaK}}$ & -0.83 & $B_{\mathrm{CaK}}$ & 3.478 & \\
${ }^{1} a_{\mathrm{CaK}}$ & -1.964 & $b_{C a K}$ & 2.520 & \\
${ }^{2} a_{\mathrm{CaK}}$ & 10.08 & $C_{C a K}$ & -211.4 & 0.025 \\
${ }^{3} a_{\mathrm{CaK}}$ & -3.57 & $c_{\mathrm{CaK}}$ & 111.6 & \\
\hline
\end{tabular}

\section{Mg/Ca exchange}

Polynomial coefficients Exponential coefficients $\ln K^{M g C a}$

\begin{tabular}{lllll}
${ }^{0} a_{\mathrm{NaK}}$ & 0.40 & $B_{\mathrm{NaK}}$ & 0.575 & \\
${ }^{1} a_{\mathrm{NaK}}$ & 0.000 & $b_{\mathrm{NaK}}$ & 0.546 & \\
${ }^{2} a_{\mathrm{NaK}}$ & 0.000 & $C_{\mathrm{NaK}}$ & -23.98 & 0.593 \\
${ }^{3} a_{\mathrm{NaK}}$ & 0.000 & $c_{\mathrm{NaK}}$ & 97.20 & \\
\hline
\end{tabular}

\section{Mg/Na exchange}

Polynomial coefficients $\quad$ Exponential coefficients $\ln K^{M g N a}$

\begin{tabular}{|c|c|c|c|c|}
\hline${ }^{0} a_{\mathrm{MgNa}}$ & 3.98 & $B_{M g N a}$ & 257.14 & \multirow{4}{*}{6.68} \\
\hline${ }^{1} a_{M g N a}$ & -9.05 & $b_{M g N a}$ & 55.11 & \\
\hline${ }^{2} a_{M g N a}$ & 6.506 & $C_{M g N a}$ & -0.329 & \\
\hline${ }^{3} a_{\mathrm{MgNa}}$ & 2.850 & $c_{M g N a}$ & 0.009 & \\
\hline \multicolumn{5}{|c|}{ Mg/K exchange } \\
\hline \multicolumn{2}{|c|}{ Polynomial coefficients } & \multicolumn{2}{|c|}{ Exponential coefficients } & $\ln K^{M g K}$ \\
\hline${ }^{0} a_{M g K}$ & 2.17 & $B_{M g K}$ & 7.65 & \multirow{4}{*}{6.72} \\
\hline${ }^{1} a_{M g K}$ & 0.287 & $b_{M g K}$ & 1.234 & \\
\hline${ }^{2} a_{M g K}$ & 0.160 & $C_{M g K}$ & -0.636 & \\
\hline${ }^{3} a_{M g K}$ & 0.220 & $c_{M g K}$ & 7.044 & \\
\hline
\end{tabular}


Table 4. Cation exchange composition and associated total normality (TN) of selected illitic samples (GAUCHER et al., 2004).

\begin{tabular}{|c|c|c|c|c|c|c|c|c|}
\hline $\begin{array}{l}\text { Litho- } \\
\text { facies }\end{array}$ & $\begin{array}{l}\text { Sample } \\
\text { name }\end{array}$ & \multicolumn{2}{|c|}{ Core levels (m) } & \multicolumn{4}{|c|}{ Cation exchange occupancy (eq/kg) } & \multirow[t]{2}{*}{$\mathrm{TN}(\mathrm{mmol} / \mathrm{L})$} \\
\hline & & & & $\mathrm{Ca}$ & $\mathrm{Mg}$ & K & $\mathrm{Na}$ & \\
\hline \multirow[t]{5}{*}{$\mathrm{C} 2 \mathrm{~b} 1$} & EST05703 & 493.47 & 493.67 & 0.065 & 0.033 & 0.012 & 0.024 & 85 \\
\hline & EST05712 & 495.50 & 495.70 & 0.061 & 0.032 & 0.012 & 0.024 & 93 \\
\hline & EST05724 & 498.47 & 498.67 & 0.066 & 0.034 & 0.013 & 0.027 & 80 \\
\hline & EST05738 & 501.50 & 501.70 & 0.066 & 0.034 & 0.012 & 0.025 & 101 \\
\hline & EST05748 & 503.93 & 504.13 & 0.064 & 0.033 & 0.013 & 0.025 & 136 \\
\hline
\end{tabular}


Table 5. Decimal logarithm of cation exchange selectivity coefficients for selected samples (Table 4) in Gaines and Thomas convention associated with calculated concentrations of $\mathrm{Na}$, $\mathrm{K}, \mathrm{Ca}$ and $\mathrm{Mg}$ in the porewater of the samples.

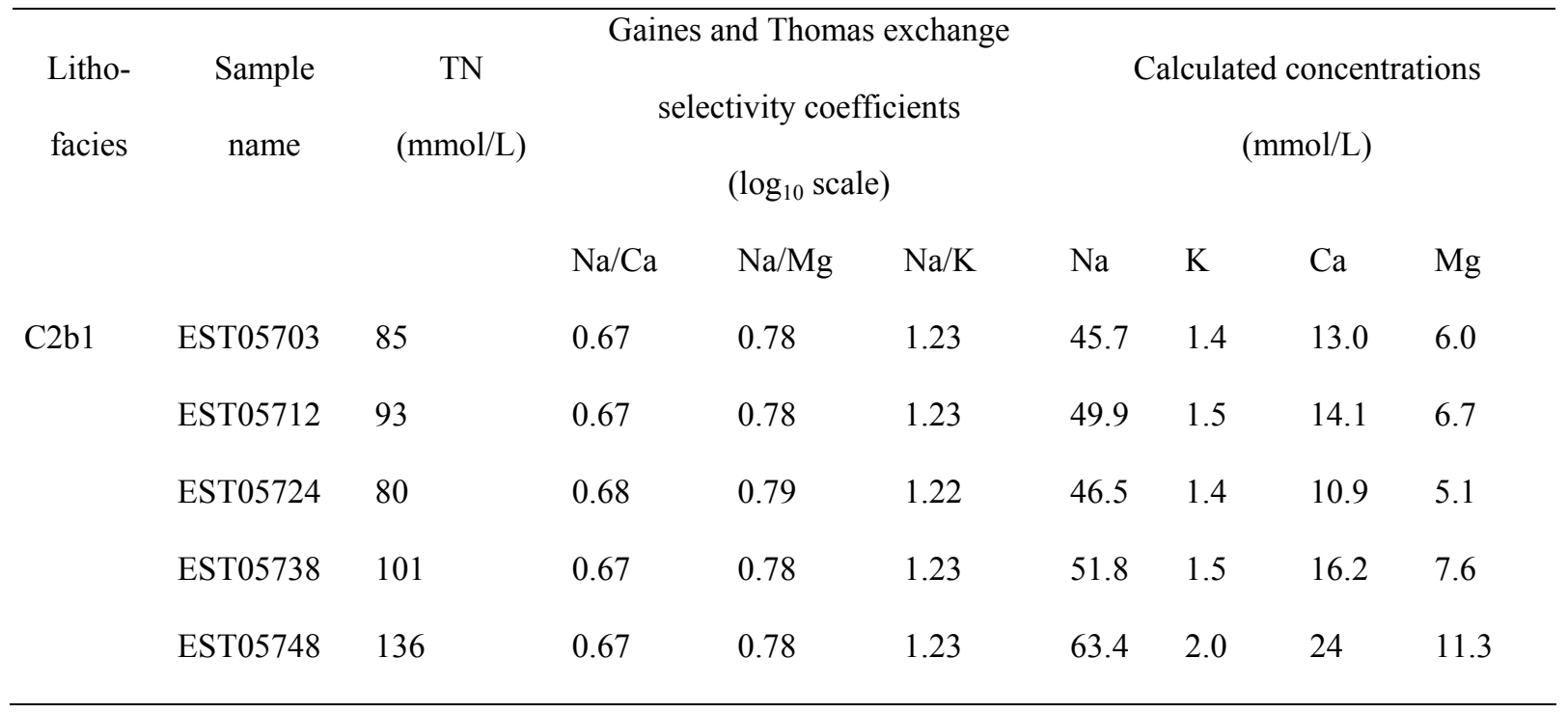




\section{Figure captions}

Fig. 1. Vanselow selectivity coefficient of $\mathrm{Na} / \mathrm{K}$ exchange as a function of the relative exchanger occupancy by K. Open circles: this study, TN (total normality) $=0.005 \mathrm{~mol} / \mathrm{L}$, $\mathrm{Na} / \mathrm{K}$ exchange experiment. Black circles: this study, $\mathrm{TN}=0.005 \mathrm{~mol} / \mathrm{L}, \mathrm{Na} / \mathrm{Ca}$ exchange experiment. Grey circles: this study, $\mathrm{TN}=0.005 \mathrm{~mol} / \mathrm{L}, \mathrm{Na} / \mathrm{Mg}$ exchange experiment. Open triangles: Thellier and Sposito, 1988, $\mathrm{TN}=0.005 \mathrm{~mol} / \mathrm{L}$. Open squares: Thellier and SpOSITO, $1989 \mathrm{~b} \mathrm{TN}=0.005 \mathrm{~mol} / \mathrm{L}$.

Fig. 2. Selectivity coefficient of $\mathrm{Na} / \mathrm{Ca}$ exchange as a function of the relative exchanger occupancy by $\mathrm{Na}$, in various thermodynamic conventions for cation exchange. Open circles: this study, $\mathrm{TN}=0.005 \mathrm{~mol} / \mathrm{L}, \mathrm{Na} / \mathrm{Ca}$ exchange experiment in presence of $\mathrm{K}(\mathrm{Mg}$ concentration was below the detection limit). Open squares: THELLIER and SPOSITO, 1989b $\mathrm{TN}=0.005 \mathrm{~mol} / \mathrm{L}, \mathrm{Na} / \mathrm{Ca}$ exchange experiment in presence of $\mathrm{K}$ and $\mathrm{Mg}$.

Fig. 3. Comparison of measured exchanger occupancies and calculated occupancies with the two-site model on illite samples at $\mathrm{TN}=0.005 \mathrm{~mol} / \mathrm{L}$. Empty circles: this study; Open squares: Thellier and Sposito, 1989b; Closed diamonds: Thellier and Sposito, 1989b; Open up-triangles: THELliER and SPOSITO, 1988; Closed up-triangles: THELLIER and SPOSITO, 1988; Open down-triangles: ThelliER and Sposito, 1988; Closed down-triangles: ThelliER and Sposito, 1988; Open diamonds: Thellier and Sposito, 1988. Some symbols may be hidden by others. Two different symbols for the same literature reference denote two different experiments in the cited reference. Full lines indicate the 1:1 relationship. See Electronic Appendix 1 for more details on the original data. 
Fig. 4. Effect of ionic strength on the $\mathrm{Na} \rightarrow \mathrm{Ca}$ selectivity coefficient for illite. Empty circles: Thellier and Sposito, 1988, $\mathrm{TN}=0.005 \mathrm{~mol} / \mathrm{L}$; Closed circles: this study, $\mathrm{TN}=0.005$ mol/L; Open squares: Thellier and Sposito, 1989b, TN $=0.002 \mathrm{~mol} / \mathrm{L}$; Closed squares: THELLIER and SPOSITO, 1989b, TN $=0.0092 \mathrm{~mol} / \mathrm{L}$.

Fig. 5. Schematic representation of $\mathrm{Na} / \mathrm{Ca}$ exchange mechanism in different site configurations.

Fig. 6. Occurrence probabilities of site configurations for $\mathrm{Na} / \mathrm{Ca}$ cation exchange. Configuration numbers refer to those given in Fig. 5.

Fig. 7. Schematic diagram of $\mathrm{Na}^{+}$and $\mathrm{Ca}^{2+}$ exchange cations retained on illite surface in a dispersed suspension (A) and in a flocculated suspension (B). Modified after MCBRIDE, 1994

Fig. 8. Percentage light transmission of an illite suspension as a function of ionic strength in a $\mathrm{Na}+\mathrm{Ca}$ or $\mathrm{Mg}$ perchlorate solute background, exchanged $\mathrm{Ca}$ or $\mathrm{Mg}$ equivalent charge representing approximately half of the exchanger composition. Circles $=\mathrm{Ca}$; Triangles $=\mathrm{Mg}$. See THELLIER and SPOSITO, 1989a for more experimental details.

Fig. 9. $\ln K_{v}{ }^{C a / K}$ values as a function of $E_{C a}$ in a Ca-Mg exchange experiment. Circles and squares: THELliER and SPOSITO, 1988, 0.005 M perchlorate. Up-pointing triangle and downpointing triangle: THELliER and Sposito, 1989b, $0.001 \mathrm{M}$ and $0.005 \mathrm{M}$ perchlorate respectively. Full lines indicate the mean of the $\ln {K_{v}}^{C a / K}$ series values. 
Fig. 10. Comparison of measured and calculated $\ln K_{v}$ values for $\mathrm{Na} / \mathrm{K}, \mathrm{Na} / \mathrm{Ca}, \mathrm{Na} / \mathrm{Mg}$, $\mathrm{Ca} / \mathrm{Mg}, \mathrm{K} / \mathrm{Ca}$ and $\mathrm{K} / \mathrm{Mg}$ exchange reactions at $\mathrm{TN} \geq 0.005 \mathrm{~mol} / \mathrm{L}$. Circles and crosses: Thellier and Sposito, 1989b, TN $=0.0092 \mathrm{~mol} / \mathrm{L}$. Squares and stars: Thellier and Sposito, $1989 \mathrm{~b}, \mathrm{TN}=0.005 \mathrm{~mol} / \mathrm{L}$. Up-pointing triangles, "plus" signs and down-pointing triangles: THELLIER and SPOSITO, 1988, TN $=0.005 \mathrm{~mol} / \mathrm{L}$. Diamonds: this study, $\mathrm{TN}=0.005$ mol/L. Some symbols hide each other. Dotted lines indicate the 1:1 relationship and one natural logarithm unit below and above.

Fig. 11. Comparison of measured and calculated $\ln K_{v}$ values for $\mathrm{Na} / \mathrm{K}, \mathrm{Na} / \mathrm{Ca}, \mathrm{Na} / \mathrm{Mg}$, $\mathrm{Ca} / \mathrm{Mg}, \mathrm{K} / \mathrm{Ca}$ and $\mathrm{K} / \mathrm{Mg}$ exchange reactions at $\mathrm{TN}<0.005 \mathrm{~mol} / \mathrm{L}$. Circles and crosses: Thellier and Sposito, 1989b, TN $=0.0036 \mathrm{~mol} / \mathrm{L}$. Squares and stars: THELliER and Sposito, 1989b, TN = $0.002 \mathrm{~mol} / \mathrm{L}$. Up-pointing triangles and "plus" signs: THELliER and Sposito, $1988, \mathrm{TN}=0.001 \mathrm{~mol} / \mathrm{L}$. Some symbols hide each other. Dotted lines indicate the 1:1 relationship and one natural logarithm unit below and above.

Fig. 12. Comparison of measured and calculated $\mathrm{Na}, \mathrm{Ca}, \mathrm{Mg}$ and $\mathrm{K}$ concentrations using the one-site model. Data from this study, SHAINBERG et al., 1980; Sposito and LEVESQUe, 1985; Thellier and SPOSITO, 1988; Thellier and SPOSITO, 1989b; ThELLIER et al., 1992. Symbols hide each other and therefore are not explained here in relation to the data source. Full lines represent the 1:1 relationship. 


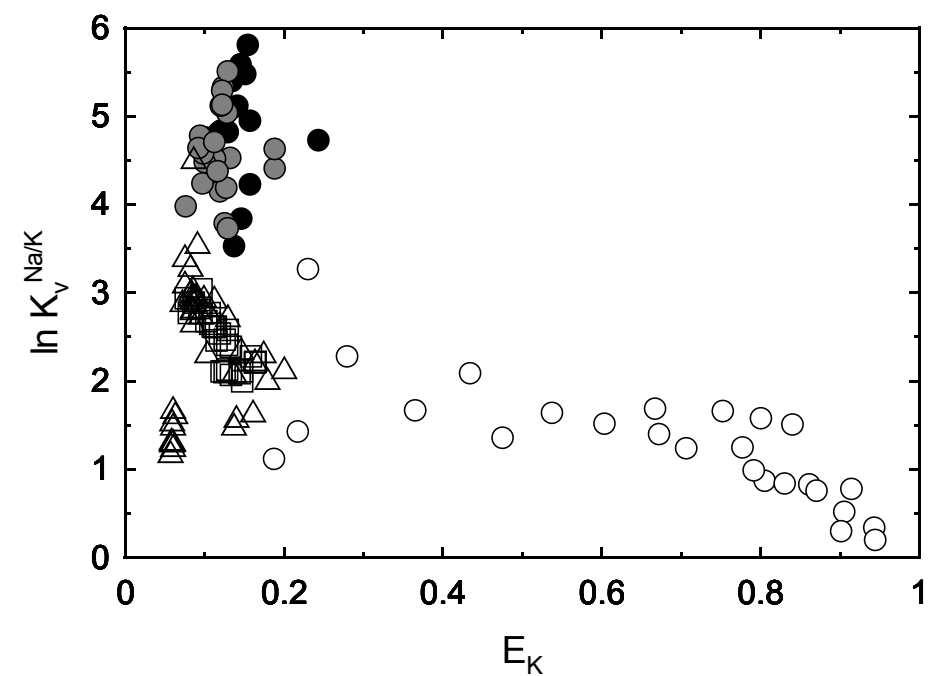

Fig. 1 

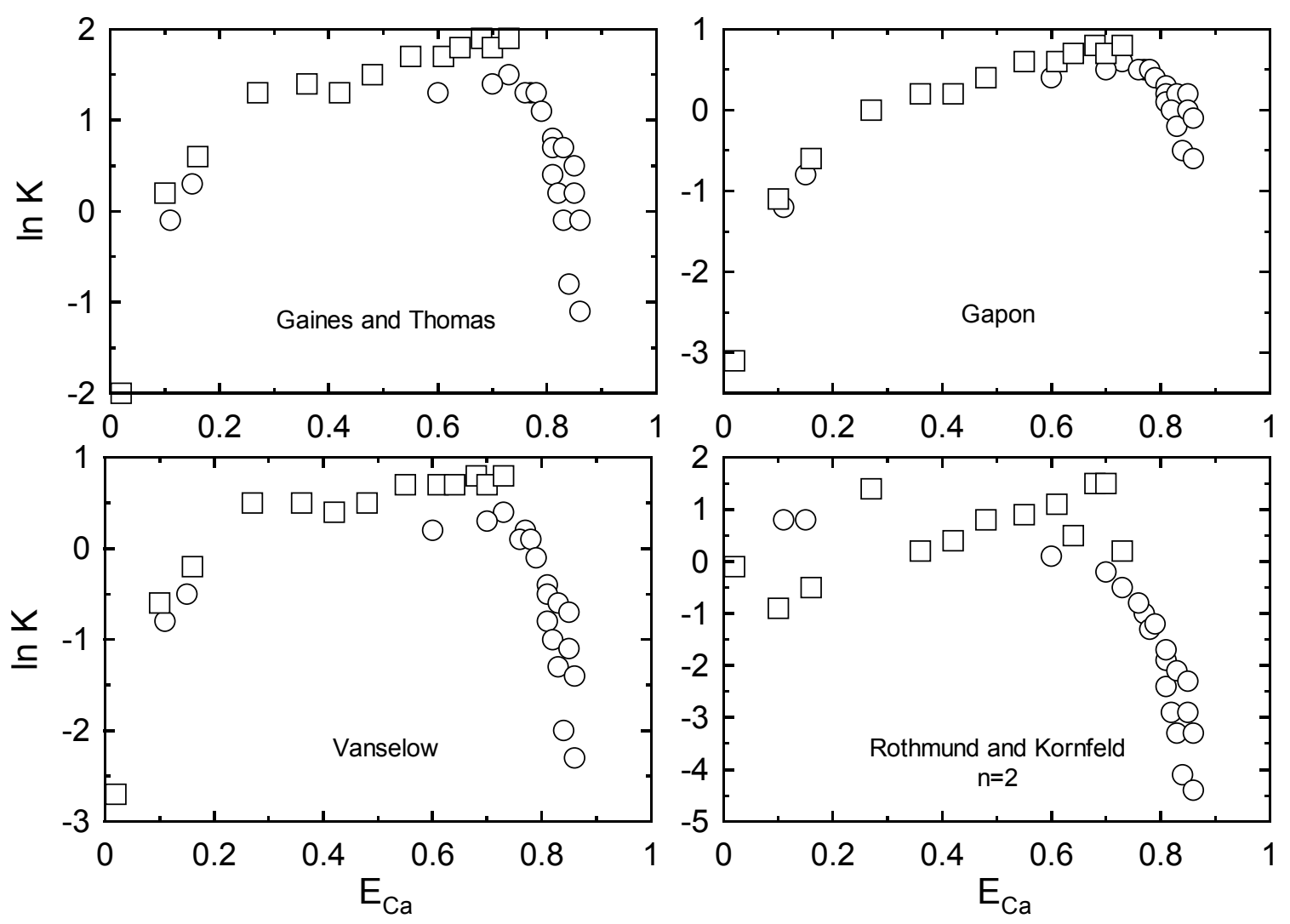

Fig. 2 

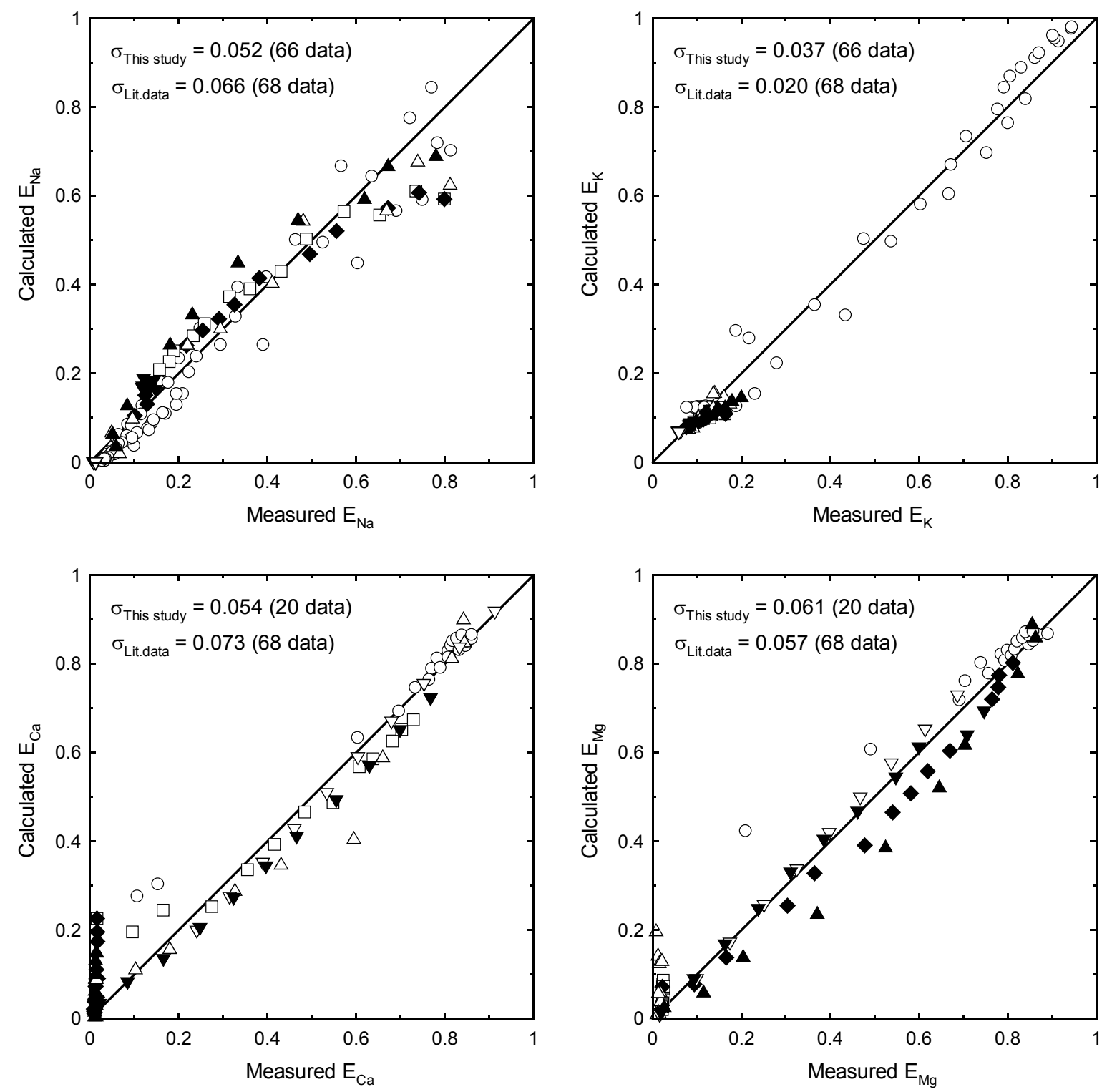

Fig. 3 


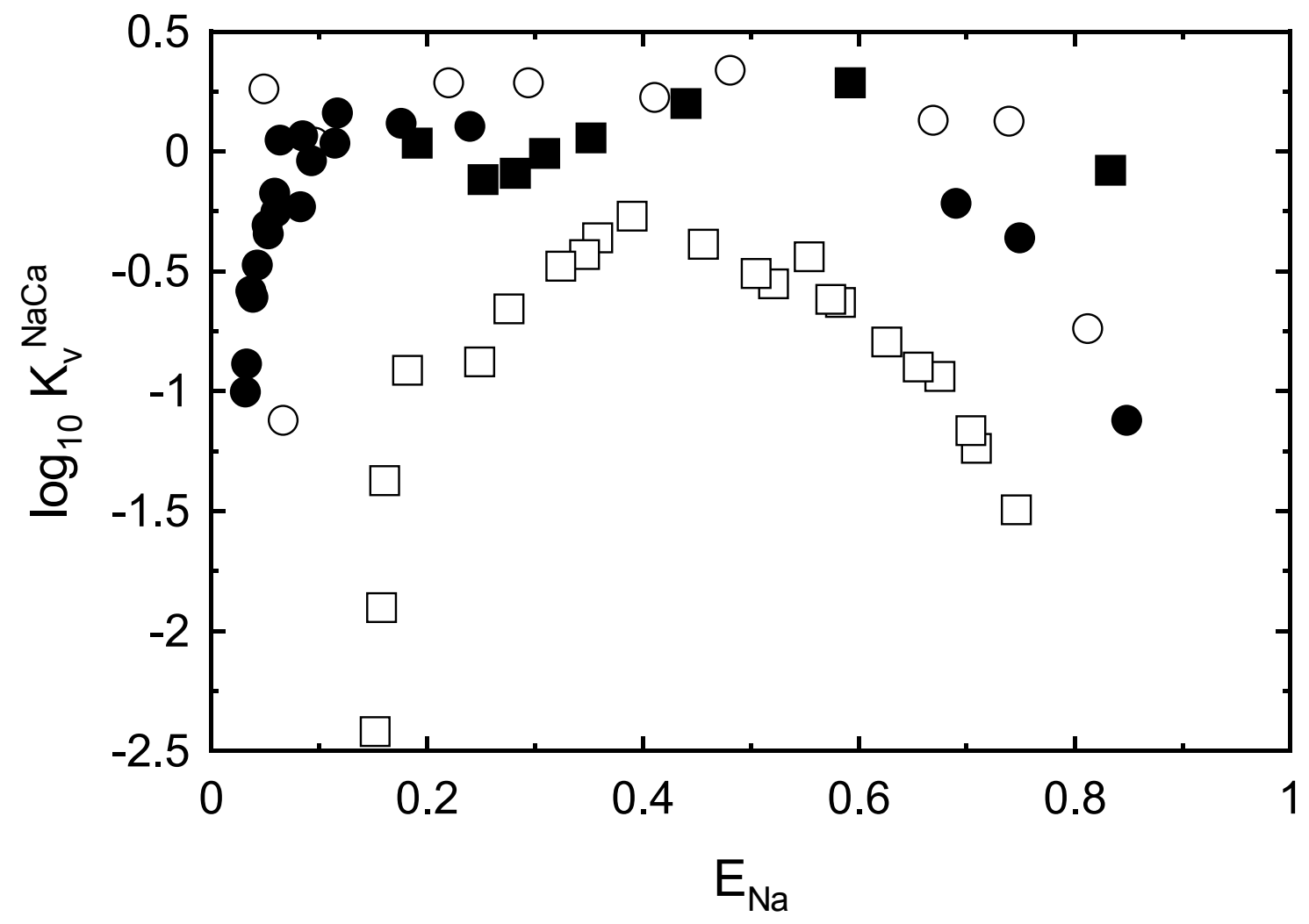

Fig. 4 


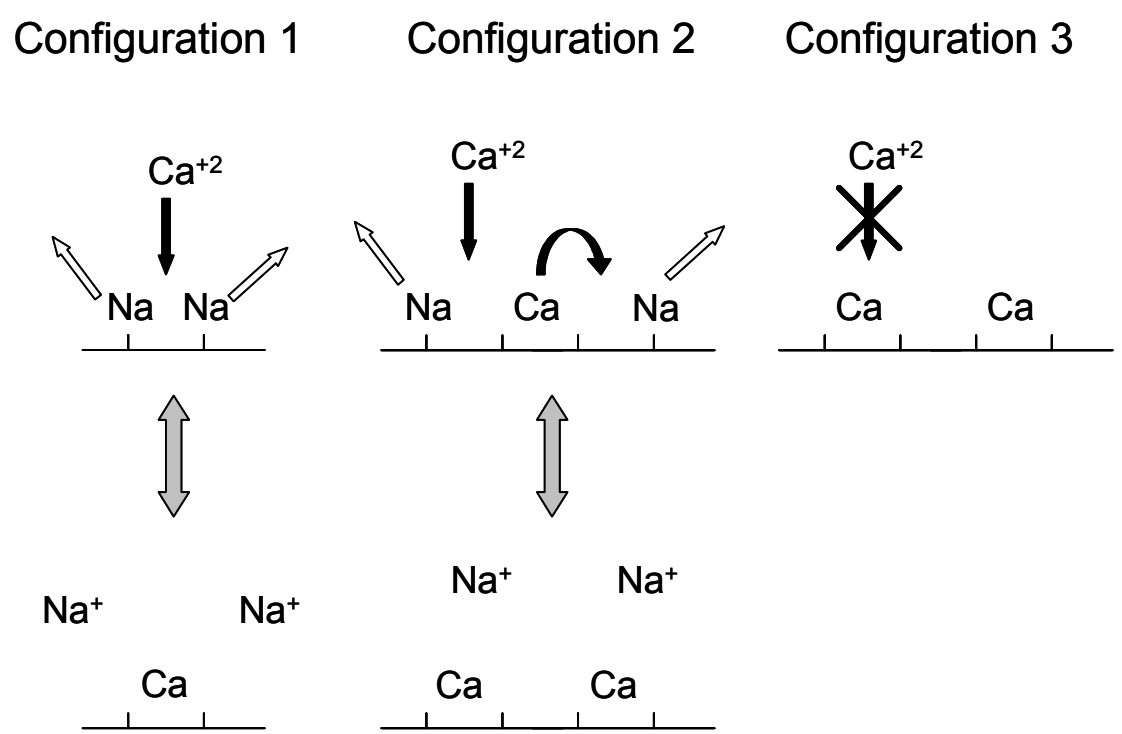

Fig. 5 


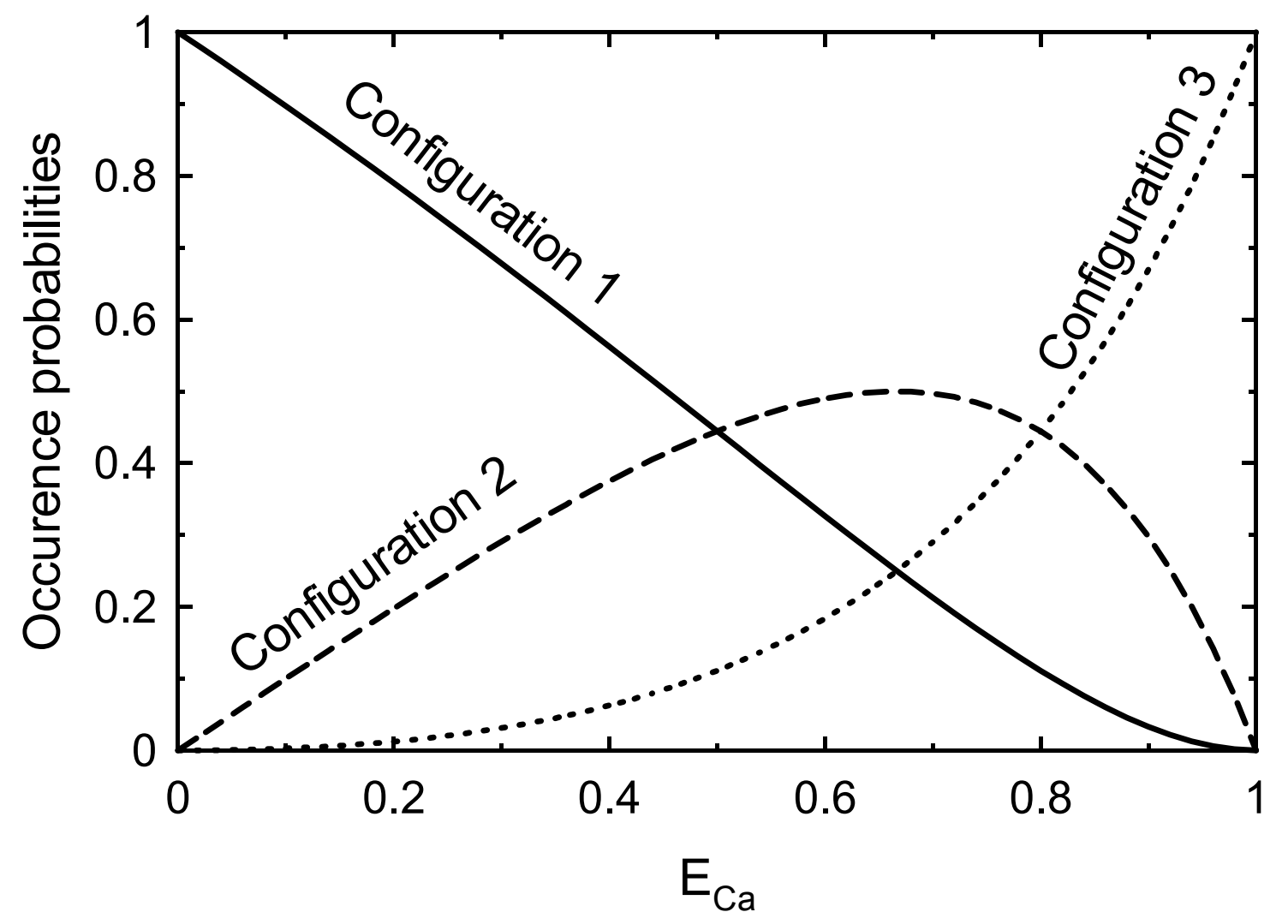

Fig. 6 
A Dispersed suspension

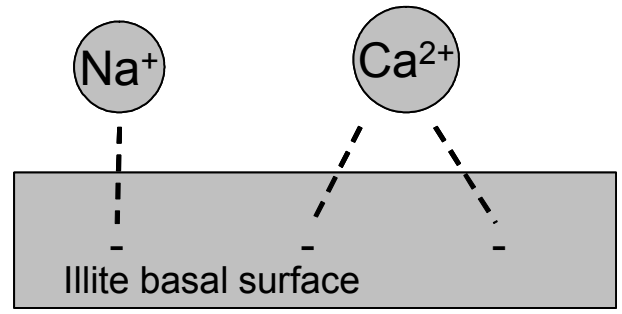

B Flocculated suspension

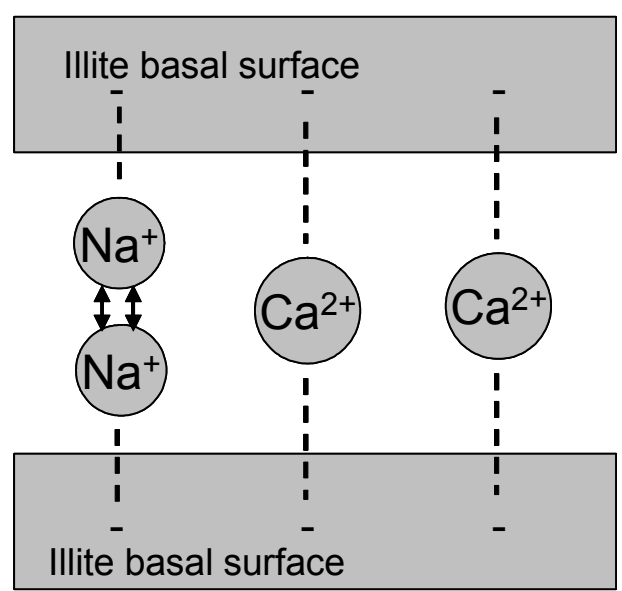

Fig. 7 


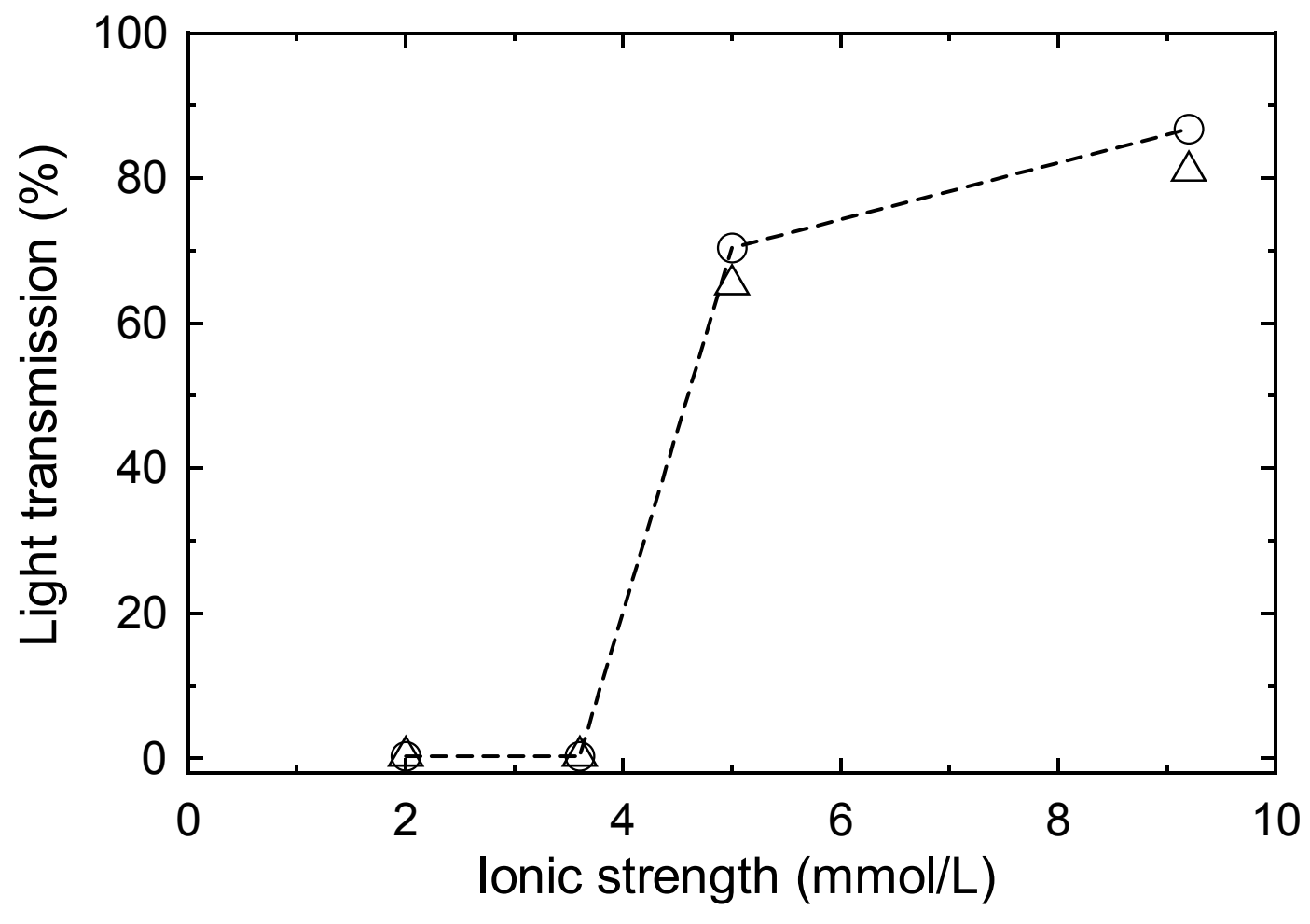

Fig. 8 


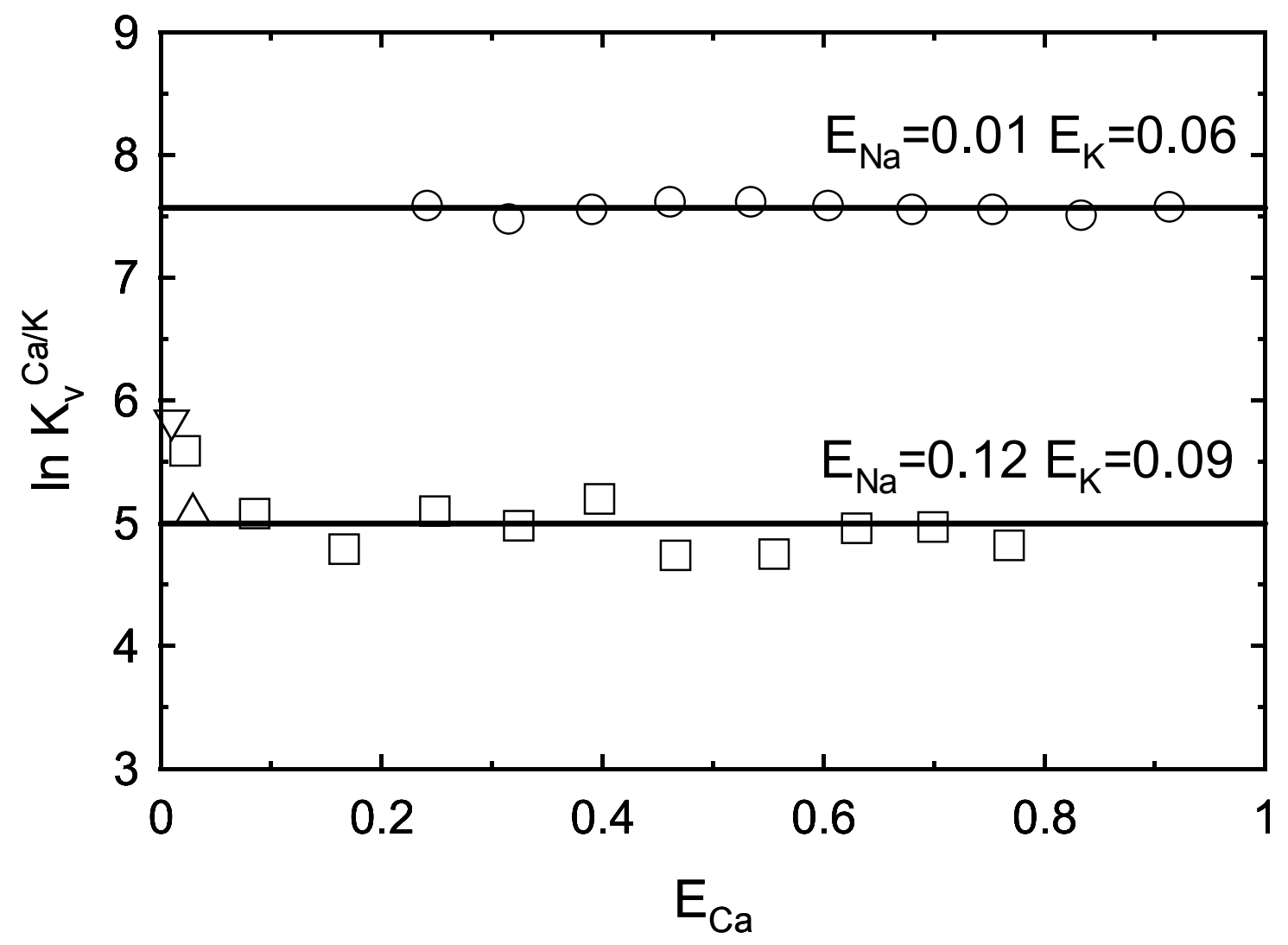

Fig. 9 

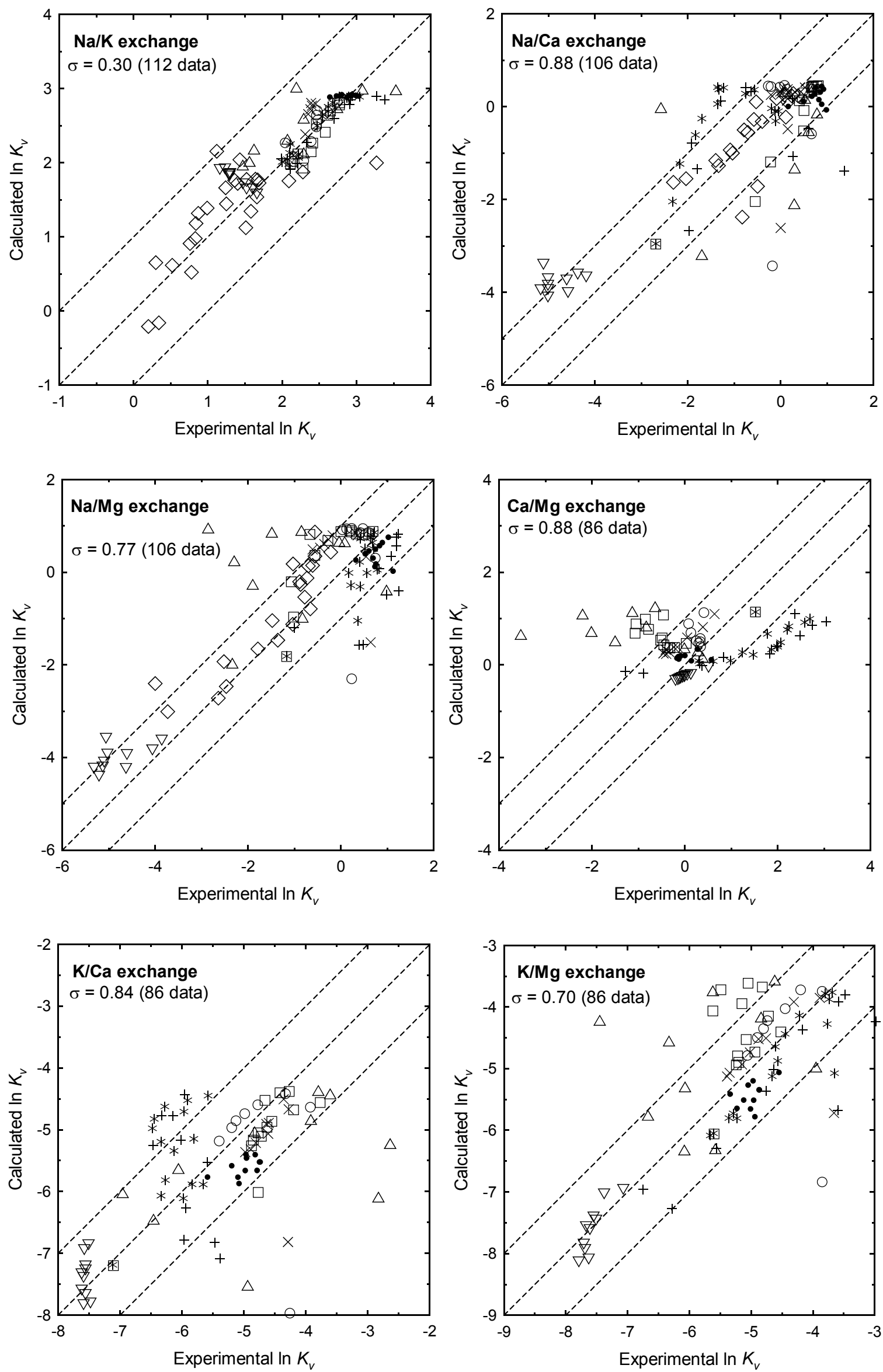

Fig. 10 

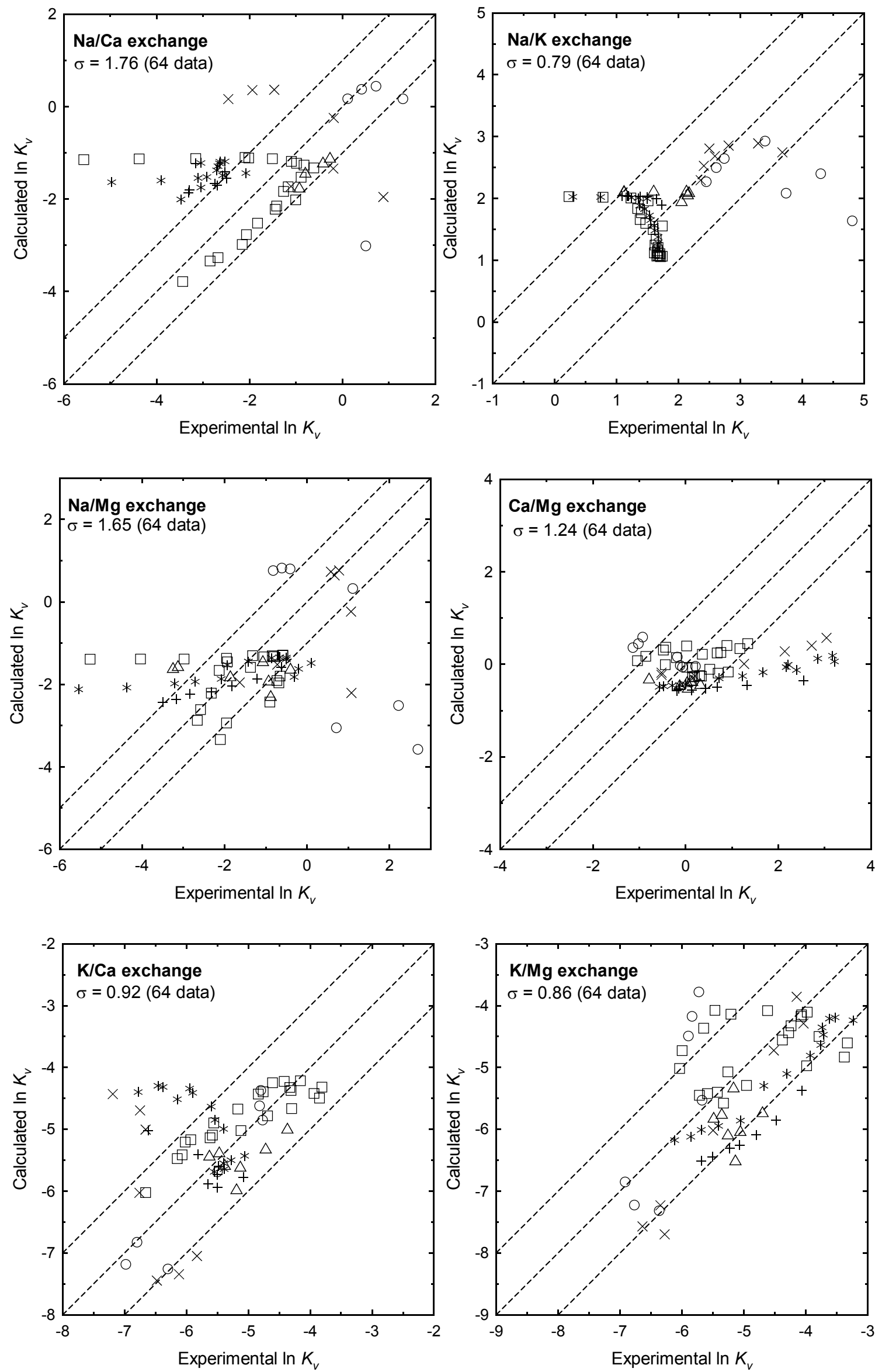

Fig. 11 

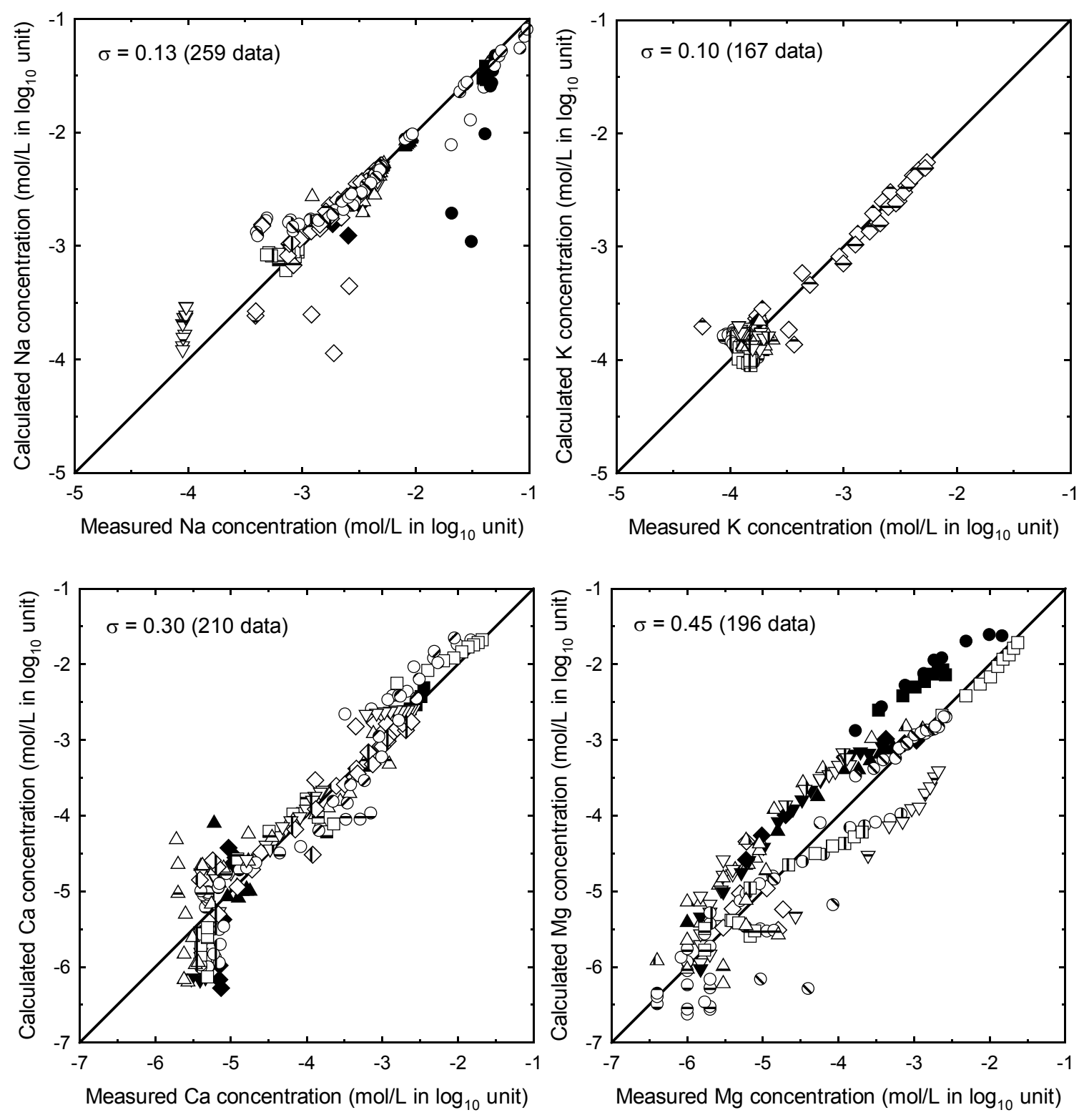

Fig. 12 